\title{
mtDNA depletion confers specific gene expression profiles in human cells grown in culture and in xenograft
}

\author{
Darren Magda1 ${ }^{1}$ Philip Lecane ${ }^{1}$, Julia Prescott ${ }^{1}$, Patricia Thiemann ${ }^{1}$, \\ Xuan Ma1, Patricia K Dranchak², Donna M Toleno², Krishna Ramaswamy², \\ Kimberly D Siegmund ${ }^{3}$ and Joseph G Hacia*2
}

Address: ${ }^{1}$ Pharmacyclics Inc., 995 East Arques Avenue, Sunnyvale, CA, 94085, USA, ${ }^{2}$ Department of Biochemistry and Molecular Biology, University of Southern California, 2250 Alcazar Street, IGM 240, Los Angeles, CA, 90089, USA and ${ }^{3}$ Department of Preventive Medicine, University of Southern California, Los Angeles, CA, 90089, USA

Email: Darren Magda - dmagda@pcyc.com; Philip Lecane - plecane@pcyc.com; Julia Prescott - jprescott@pcyc.com; Patricia Thiemann - tthiemann@pcyc.com; Xuan Ma - xma@pcyc.com; Patricia K Dranchak - pdrancha@usc.edu; Donna M Toleno - toleno@usc.edu; Krishna Ramaswamy - rkrishna@usc.edu; Kimberly D Siegmund - kims@usc.edu; Joseph G Hacia* - hacia@ hsc.usc.edu

* Corresponding author

Published: 3 November 2008

BMC Genomics 2008, 9:521 doi:10.1|86/147|-2|64-9-521
Received: 17 July 2008

Accepted: 3 November 2008

This article is available from: http://www.biomedcentral.com/l47I-2164/9/52I

(c) 2008 Magda et al; licensee BioMed Central Ltd.

This is an Open Access article distributed under the terms of the Creative Commons Attribution License (http://creativecommons.org/licenses/by/2.0), which permits unrestricted use, distribution, and reproduction in any medium, provided the original work is properly cited.

\begin{abstract}
Background: Interactions between the gene products encoded by the mitochondrial and nuclear genomes play critical roles in eukaryotic cellular function. However, the effects mitochondrial DNA ( $m t D N A)$ levels have on the nuclear transcriptome have not been defined under physiological conditions. In order to address this issue, we characterized the gene expression profiles of A549 lung cancer cells and their mtDNA-depleted $\rho^{0}$ counterparts grown in culture and as tumor xenografts in immune-deficient mice.

Results: Cultured A549 $\rho^{0}$ cells were respiration-deficient and showed enhanced levels of transcripts relevant to metal homeostasis, initiation of the epithelial-mesenchymal transition, and glucuronidation pathways. Several well-established HIF-regulated transcripts showed increased or decreased abundance relative to the parental cell line. Furthermore, growth in culture versus xenograft has a significantly greater influence on expression profiles, including transcripts involved in mitochondrial structure and both aerobic and anaerobic energy metabolism. However, both in vitro and in vivo, mtDNA levels explained the majority of the variance observed in the expression of transcripts in glucuronidation, tRNA synthetase, and immune surveillance related pathways. mtDNA levels in A549 xenografts also affected the expression of genes, such as AMACR and PHYH, involved in peroxisomal lipid metabolic pathways.

Conclusion: We have identified mtDNA-dependent gene expression profiles that are shared in cultured cells and in xenografts. These profiles indicate that $m t D N A$-depleted cells could provide informative model systems for the testing the efficacy of select classes of therapeutics, such as antiangiogenesis agents. Furthermore, mtDNA-depleted cells grown culture and in xenografts provide a powerful means to investigate possible relationships between mitochondrial activity and gene expression profiles in normal and pathological cells.
\end{abstract}




\section{Background}

The discovery that mammalian cells grown in the presence of inhibitors of mitochondrial DNA (mtDNA) replication and transcription can lose all or almost all their mtDNA has provided a powerful means to study interactions between the mitochondrial and nuclear genomes, reviewed in [1-4]. The human mitochondrial genome is 16,569-bp in length and encodes $12 \mathrm{~S}$ and 16S rRNAs, 22 tRNAs, and 13 polypeptides involved in the respiratory electron transport chain and ATP synthesis. The comprehensive MitoP2 database of human mitochondrial proteins http://www.mitop.de:8080/mitop2/ showhumanmask.do lists 870 human mitochondrial proteins encoded by the nuclear genome [5]. Proteomic and systems biology approaches will likely unearth additional proteins directly involved in human mitochondrial function [6]. However, fundamental questions will remain about the influences mtDNA has on the regulation of nuclear genes in vivo.

mtDNA-depleted $\rho^{0}$ cell lines are auxotrophic for pyruvate and uridine, and are incapable of aerobic respiration due to the lack of key respiratory chain components $[7,8]$. Nonetheless, mtDNA-depleted cell lines possess distorted mitochondria-like structures comprised of nuclearencoded mitochondrial proteins [9-11] and demonstrate increased invasive behavior in culture [12-17] Furthermore, mtDNA-depleted cells can grow as tumor xenografts in immune-deficient mice in some instances $[18,19]$, but not others [20].

Here, we generated mtDNA-depleted A549 $\rho^{0}$ lung cancer cells and validated their genetic and biochemical properties in culture and tumor xenografts. Our gene expression profiling analyses of parental A549 and A549 $\rho^{0}$ cells uncovered differential expression of transcripts relevant to immune recognition, autophagy of defective mitochondria, HIF-mediated gene regulation, the epithelial-mesenchymal transition (EMT), and elimination of lipophilic molecules. Furthermore, growth in culture versus in xenograft had a greater effect on the A549 transcriptome, especially nuclear-encoded genes important for mitochondrial function and energy metabolism, than the presence of mtDNA. Overall, mtDNA-depleted cells grown in culture and in xenograft provide complementary means to identify relationships between mitochondrial activity and cellular gene expression profiles that could serve as potential biomarkers of disease.

\section{Methods}

\section{Cells and cell culture reagents}

A549 lung cancer cells were obtained from the American Type Culture Collection. Unless otherwise indicated, all cell culture reagents were purchased from Invitrogen. mtDNA-deficient A549 $\rho^{0}$ cell cultures were prepared by serial passage of parental A549 cells for 28 population doublings in standard growth media (RPMI 1640 medium supplemented with $20 \mathrm{mM}$ HEPES, $2 \mathrm{mM} \mathrm{L-}$ glutamine, $10 \%$ heat inactivated fetal bovine serum (Hyclone), $200 \mathrm{U} / \mathrm{mL}$ penicillin, and $200 \mu \mathrm{g} / \mathrm{mL}$ streptomycin) in the presence of ethidium bromide (100 ng/ $\mathrm{mL})$, sodium pyruvate $(1 \mathrm{mM})$, and uridine $(50 \mu \mathrm{g} / \mathrm{mL})$. The glucose concentration in the standard growth media is approximately $11 \mathrm{mM}$. All subsequent experiments employing A549 and A549 $\rho^{0}$ cell cultures were conducted in the same standard growth media supplemented only with sodium pyruvate $(1 \mathrm{mM})$ and uridine $(50 \mu \mathrm{g} / \mathrm{mL})$. Growth curves were obtained by Coulter counting. All experiments were conducted using cell culture populations and not purified clones.

\section{Estimation of mtDNA levels}

mtDNA levels in A549 or A549 $\rho^{0}$ cell cultures were estimated using the pseudogene ratioing method [21]. Briefly, total DNA (both mitochondrial and genomic) was extracted from A549 or A549 $\rho^{0}$ cell cultures using the QIAamp DNA Mini Kit (Qiagen). These served as templates for PCR amplification using primers designed to anneal either to mtDNA or a previously described DNAembedded mtDNA pseudogene (mtDNA $\psi$ ) [22]. Amplicons derived from either nuclear DNA-embedded mtDNA pseudogene or mtDNA templates are predicted to be approximately the same length, but differ in sequence. These amplicons served as templates for a nested PCR using primers designed to amplify both the mtDNAencoded MT-CO2 and the nuclear DNA-embedded $\mathrm{mtD}$ $\mathrm{NA} \psi$ sequences. The resulting amplicons were subcloned using the StrataClone ${ }^{\mathrm{TM}}$ PCR cloning system (Stratagene). Plasmid DNA from individual colonies was prepared for sequencing using the illustra TempliPhi 100/500 DNA Amplification Kit (GE Healthcare). The resulting products were sequenced using BigDye Terminator v3.0 from Applied Biosystems diluted with halfBD (Genetix Ltd.), according to manufacturer's recommendations. We obtained sequence information from 70 colonies derived from A549 DNA templates (all showed mtDNA sequences) and 92 colonies derived from A549 $\rho^{0}$ DNA templates (all showed mtDNA $\psi$ sequences). mtDNA abundance in the original A549 or A549 $\rho^{0}$ DNA preparation was estimated based on the number of colonies showing mtDNA or mtDNA $\psi$ sequences, as previously described [21].

\section{Oxygen consumption}

Oxygen consumption rates were measured using a Clarktype electrode [23]. In brief, plateau phase cultures of A549 or A549 $\rho^{0}$ cells were treated with antimycin A $(1 \mu \mathrm{g} /$ $\mathrm{mL}$ ) or control vehicle for 3 hours. After medium was removed, cells were washed with Hanks balanced salt solution (HBSS), and harvested using trypsin/EDTA. Cells 
were resuspended in complete medium, stored on ice, and aliquots were removed for Coulter counting and viability (defined as ability to exclude propidium iodide). Prior to measurement, an aliquot of cell suspension (ca. $1 \times 10^{7}$ cells $/ \mathrm{mL}$ ) was incubated at $37^{\circ} \mathrm{C}$ for 2 minutes, and then transferred to the sealed electrode chamber of an Oxytherm apparatus (Hansatech, Norfolk, UK) to measure dissolved oxygen concentration. Background oxygen consumption by the electrode in the absence of cells was subtracted from all measurements.

\section{Quantitative RT-PCR analysis}

RNA was obtained from cultured A549 cells or harvested from tumor specimens as described [24]. Total RNA was quantified using the Ribogreen RNA quantitation kit (Molecular Probes). One-step RT-PCR assays were set up in triplicate according to manufacturer's instructions using the Taqman master mix (Applied Biosystems, Inc.) and 50 ng of total RNA as template. The amount of RNA in each well was re-quantified and used for normalizations. Gene expression assay probe sets for $\beta$-actin, MT$A T P 6$, and MT-CYB were purchased from Applied Biosystems and assays were performed on an ABI PRISM 7300 instrument according to standard protocols.

\section{ELISA and Western blotting}

Total HIF-1a protein was detected by sandwich ELISA using the DuoSet IC ${ }^{\mathrm{TM}}$ HIF-1a ELISA kit obtained from R\&D Systems. Briefly, 96-well plates were coated with HIF-1a capture antibody overnight prior to blocking with $5 \%$ BSA in wash buffer. Protein lysates (50 $\mu$ g protein per well prepared according to the manufacturer's instructions) were added for 2 hours, whereupon plates were washed and a biotinylated detection antibody specific for HIF-1a was added. A streptavidin-horseradish peroxidase format was used for detection. The optical density at 450 minus $570 \mathrm{~nm}$ was measured using a microplate reader (SpectraMax Plus). HIF-1a concentrations were calculated by linear regression using a standard curve prepared from HIF-1a standard supplied with the ELISA kit.

Western blotting was performed using antibodies against GLUT1 (aka SLC2A1, rabbit polyclonal), PGK1 (goat polyclonal), MTCO2 (mouse monoclonal), PDK1 (rabbit polyclonal), and DDIT4 (rabbit polyclonal) obtained from Santa Cruz Biotechnology, Molecular Probes, Stressgen, and Proteintech, respectively. All membranes were blotted with an anti-Hsc70 (mouse monoclonal, Santa Cruz Biotechnology) antibody to control for loading and transfer. HRP-conjugated goat anti-rabbit and goat antimouse secondary antibodies were from Pierce. HRP-conjugated donkey anti-goat secondary antibody was from Santa Cruz Biotechnology. HRP substrate was from Pierce. Bands were imaged and quantified in the linear range and normalized to Hsc70, using the ChemiDoc XRS Imaging System (BioRad Laboratories, Inc.).

\section{Gene expression profiling in cell culture}

A549 or A549 $\rho^{0}$ human lung cancer cells $\left(1 \times 10^{5}\right.$ cells per T-25 flask in $7 \mathrm{~mL}$ complete RPMI 1640 medium) were seeded 8 days prior to RNA isolation. Each experiment was performed in triplicate. After incubation, all cultures were washed twice with HBSS supplemented with $0.5 \%$ BSA and total RNA was isolated and subjected to analysis on Human Genome U133A Arrays (Affymetrix), as described $[24,25]$. ArrayAssist software (Stratagene) was used to generate scaled $\log 2$ transformed gene expression scores based on the RMA algorithm and to conduct hierarchical clustering analyses, as previously described [24]. Probe sets with a $>1.5$-fold differential expression (twotailed Student's t-test $P<0.01$ subjected to Benjamini and Hochberg correction for multiple comparisons, and $>20$ unit difference in the geometric mean expression scores) in a comparison of interest are reported.

We used analysis of variance to estimate the proportion of variance explained by mtDNA status and explained by growth conditions, in the gene expression profiles from A549 $\rho^{0}$ and parental A549 cells grown in culture and in xenografts. Statistical significance is determined using the Bayes Moderated F test [26] implemented using the limma package in Bioconductor [27]. This uses an empirical Bayes approach, providing more stable inference when the number of arrays is small. $P$-values are adjusted for multiple comparisons using the Benjamini and Hochberg approach to control the false-discovery rate [28].

GeneOntology and KEGG analyses were conducted using WebGestalt software http://bioinfo.vanderbilt.edu/web gestalt/[29-31]. All scaled fluorescent intensity values and .cel files are available at the National Center for Biotechnology Information (NCBI) Gene Expression Omnibus (GEO) repository http://www.ncbi.nlm.nih.gov/geo/ under Series Accession Number GSE10957. In addition, all scaled fluorescent intensity values are available in Supplemental Table 1.

\section{Gene expression profiling in mouse xenograft models}

Animal care was in accordance with NIH and institutional guidelines. For the A549 xenograft model, 1.7 million A549 cells were injected subcutaneously/intramuscularly into the right hind flank of 6 week old CD-1 nude mice that had been irradiated with 4 Gy of total body irradiation from a ${ }^{137} \mathrm{Cs}$ radiation source one day prior to tumor implantation [32]. For the A549 $\rho^{0}$ xenograft model, 1.5 million cells were used. Tumor and body weight measurements ( 6 or 7 mice per group) were performed three times per week once tumors became palpable. This occurred 41 versus 9 days post-implantation in $\rho^{0}$ and parental A549 
Table I: Transcripts where $90 \%$ of the variance in gene expression is explained by mtDNA status

\begin{tabular}{|c|c|c|c|c|c|c|c|c|c|c|}
\hline & \multirow[t]{2}{*}{$\begin{array}{l}\text { Affymetrix Probe } \\
\text { ID }\end{array}$} & \multirow[t]{2}{*}{ Gene Symbol } & \multirow[t]{2}{*}{ Entrez GenelD } & \multirow[t]{2}{*}{ Gene Description } & \multirow[t]{2}{*}{$\begin{array}{l}\rho^{0} \text { Proportion of } \\
\text { Variance }^{\mathrm{a}}\end{array}$} & \multirow[t]{2}{*}{$F$ test $^{b}$} & \multicolumn{2}{|c|}{$\rho^{0}$ Vitro/A549 Vitro } & \multicolumn{2}{|c|}{$\begin{array}{c}\rho^{0} \text { Vivo/A549 } \\
\text { Vivo }\end{array}$} \\
\hline & & & & & & & $\mathrm{FCc}$ & $P d$ & $\mathrm{FCc}$ & $P d$ \\
\hline \multirow{28}{*}{$\begin{array}{l}\text { Up-regulated in } \\
\rho^{0} \text { cells }\end{array}$} & 214247_s_at & DKK3 & 27122 & dickkopf homolog 3 & 0.98 & $8.62 \times 10^{-11}$ & 4.4 & 0.0009 & 3.7 & 0.0005 \\
\hline & 209822_s_at & $V L D L R$ & 7436 & $\begin{array}{l}\text { very low density lipoprotein } \\
\text { receptor }\end{array}$ & 0.98 & $7.05 \times 10^{-10}$ & 3.3 & 0.0057 & 2.7 & 0.0002 \\
\hline & 210105_s_at & FYN & 2534 & FYN oncogene & 0.97 & $9.85 \times 10^{-9}$ & 3.4 & 0.0082 & 2.7 & 0.0009 \\
\hline & 221305_s_at & UGTIA8 & 54576 & $\begin{array}{l}\text { UDP glucuronosyltransferase I } \\
\text { family }\end{array}$ & 0.97 & $1.21 \times 10^{-8}$ & 8.3 & 0.0088 & 13.1 & 0.0007 \\
\hline & 202242_at & TSPAN7 & 7102 & tetraspanin 7 & 0.96 & $3.45 \times 10^{-11}$ & 9.3 & 0.0046 & 9.3 & 0.0005 \\
\hline & 205II9_s_at & FPRI & 2357 & formyl peptide receptor I & 0.96 & $3.82 \times 10^{-9}$ & 3.8 & 0.0045 & 4.8 & 0.0010 \\
\hline & 208596_s_at & UGTIAIO & 54575 & $\begin{array}{l}\text { UDP glucuronosyltransferase I } \\
\text { family }\end{array}$ & 0.96 & $1.20 \times 10^{-10}$ & 6.2 & 0.0051 & 10.2 & 0.0001 \\
\hline & 219093_at & PIDI & 55022 & hypothetical protein FLJ2070I & 0.95 & $1.41 \times 10^{-8}$ & 5.4 & 0.0090 & 4.2 & 0.0020 \\
\hline & 209040_s_at & PSMB8 & 5696 & proteasome subunit & 0.95 & $2.73 \times 10^{-10}$ & 3.2 & 0.0048 & 2.9 & 0.0003 \\
\hline & 206094_x_at & UGTIAG & 54578 & $\begin{array}{l}\text { UDP glucuronosyltransferase I } \\
\text { family }\end{array}$ & 0.95 & $6.79 \times 10^{-11}$ & 5.9 & 0.0041 & 9.7 & 0.0001 \\
\hline & 219959_at & PTHLH & 55034 & parathyroid hormone-like hormone & 0.94 & $2.77 \times 10^{-9}$ & 2.8 & 0.0079 & 3.1 & 0.0005 \\
\hline & 201042_at & TGM2 & 7052 & transglutaminase 2 & 0.94 & $1.64 \times 10^{-6}$ & 1.6 & 0.0245 & 1.6 & 0.0014 \\
\hline & 207|26_x_at & UGTIA4 & 54657 & $\begin{array}{l}\text { UDP glucuronosyltransferase I } \\
\text { family }\end{array}$ & 0.93 & $3.45 \times 10^{-11}$ & 6.7 & 0.0048 & 11.5 & 0.0000 \\
\hline & 203II3_s_at & EEFID & 1936 & $\begin{array}{l}\text { eukaryotic translation elongation } \\
\text { factor }\end{array}$ & 0.92 & $1.10 \times 10^{-5}$ & 1.5 & 0.0291 & 1.6 & 0.0042 \\
\hline & 204802_at & RRAD & 6236 & Ras-related associated with diabetes & 0.92 & $9.09 \times 10^{-7}$ & 2.5 & 0.0289 & 2.7 & 0.0044 \\
\hline & 215|25_s_at & UGTIAIO & 54575 & $\begin{array}{l}\text { UDP glucuronosyltransferase I } \\
\text { family }\end{array}$ & 0.92 & $8.62 \times 10^{-11}$ & 7.2 & 0.0045 & 12.7 & 0.0001 \\
\hline & 213587_s_at & ATP6V0E2 & 155066 & $\begin{array}{l}\text { ATPase, } \mathrm{H}+\text { transporting } \mathrm{V} 0 \text { subunit } \\
\mathrm{e} 2\end{array}$ & 0.92 & $3.60 \times 10^{-6}$ & 1.7 & 0.0447 & 1.9 & 0.0021 \\
\hline & 217739_s_at & PBEFI & 10135 & pre-B-cell colony enhancing factor I & 0.91 & $4.54 \times 10^{-7}$ & 3.8 & 0.0141 & 11.0 & 0.0004 \\
\hline & 204532_x_at & UGTIA4 & 54657 & $\begin{array}{l}\text { UDP glucuronosyltransferase I } \\
\text { family }\end{array}$ & 0.91 & $3.96 \times 10^{-10}$ & 5.8 & 0.0055 & 10.9 & 0.0000 \\
\hline & 212160_at & XPOT & 11260 & exportin, tRNA & 0.91 & $1.52 \times 10^{-5}$ & 1.6 & 0.0524 & 1.9 & 0.0015 \\
\hline & 212307_s_at & OGT & 8473 & GlcNAc transferase & 0.91 & $6.52 \times 10^{-7}$ & 1.7 & 0.0273 & 2.4 & 0.0007 \\
\hline & 203262_s_at & FAM50A & 9130 & family with sequence similarity 50 & 0.91 & $3.01 \times 10^{-5}$ & 1.5 & 0.0435 & 1.6 & 0.0030 \\
\hline & 217738_at & PBEFI & 10135 & pre-B-cell colony enhancing factor I & 0.91 & $1.76 \times 10^{-7}$ & 4.5 & 0.0054 & 11.2 & 0.0007 \\
\hline & 201462_at & SCRNI & 9805 & secernin I & 0.90 & $2.79 \times 10^{-5}$ & 1.4 & 0.0186 & 1.5 & 0.0032 \\
\hline & 219762_s_at & RPL36 & 25873 & ribosomal protein L36 & 0.90 & $8.04 \times 10^{-6}$ & 1.4 & 0.0073 & 1.7 & 0.0014 \\
\hline & 212909_at & LYPDI & 116372 & LY6/PLAUR domain containing I & 0.90 & $1.04 \times 10^{-5}$ & 2.5 & 0.0069 & 1.7 & 0.0050 \\
\hline & 215025_at & NTRK3 & 4916 & $\begin{array}{l}\text { neurotrophic tyrosine kinase, } \\
\text { receptor }\end{array}$ & 0.90 & $6.53 \times 10^{-7}$ & 2.6 & 0.0179 & 2.2 & 0.0048 \\
\hline & 20I474_s_at & ITGA3 & 3675 & integrin, alpha 3 & 0.90 & $1.57 \times 10^{-6}$ & 1.8 & 0.0491 & 1.8 & 0.0018 \\
\hline \multirow[t]{2}{*}{$\begin{array}{l}\text { Down-regulated } \\
\text { in } \rho^{0} \text { cells }\end{array}$} & 211600_at & MT-ND5 & 4540 & $\begin{array}{l}\text { mito. encoded } \mathrm{NADH} \\
\text { dehydrogenase } 5\end{array}$ & 0.99 & $4.48 \times 10^{-14}$ & -73.7 & 0.0007 & -46.9 & 0.0001 \\
\hline & 205674_x_at & FXYD2 & 486 & $\begin{array}{l}\text { FXYD domain ion transport } \\
\text { regulator } 2\end{array}$ & 0.98 & $3.45 \times 10^{-11}$ & -11.0 & 0.0029 & -14.8 & 0.0004 \\
\hline
\end{tabular}


Table I: Transcripts where $\mathbf{9 0 \%}$ of the variance in gene expression is explained by mtDNA status (Continued)

\begin{tabular}{|c|c|c|c|c|c|c|c|c|c|}
\hline 21I203_s_at & CNTNI & 1272 & contactin I & 0.97 & $4.65 \times 10^{-9}$ & -4.7 & 0.0009 & -3.6 & 0.0015 \\
\hline 204698_at & ISG20 & 3669 & $\begin{array}{l}\text { interferon stimulated exonuclease } \\
\text { gene }\end{array}$ & 0.96 & $3.67 \times 10^{-8}$ & -3.5 & 0.0056 & -2.9 & 0.0014 \\
\hline 210065_s_at & UPKIB & 7348 & uroplakin IB & 0.95 & $4.17 \times 10^{-8}$ & -4.3 & 0.0071 & -6.2 & 0.0013 \\
\hline 203108_at & GPRC5A & 9052 & G protein-coupled receptor & 0.95 & $4.96 \times 10^{-9}$ & -3.4 & 0.0048 & -5.9 & 0.0001 \\
\hline 207434_s_at & FXYD2 & $4|5|$ & $\begin{array}{l}\text { FXYD domain ion transport } \\
\text { regulator } 2\end{array}$ & 0.95 & $2.29 \times 10^{-11}$ & -9.8 & 0.0063 & -12.9 & 0.0003 \\
\hline 201065_s_at & GTF2I & 2969 & general transcription factor II, i & 0.95 & $6.30 \times 10^{-7}$ & -2.0 & 0.0109 & -1.7 & 0.0010 \\
\hline 210064_s_at & UPKIB & 7348 & uroplakin IB & 0.95 & $1.51 \times 10^{-8}$ & -5.8 & 0.0081 & -5.9 & 0.0020 \\
\hline 222088_s_at & SLC2A3 & 6515 & solute carrier family 2 , member 3 & 0.95 & $1.46 \times 10^{-8}$ & -2.1 & 0.0080 & -2.4 & 0.0010 \\
\hline 33304_at & ISG20 & 3669 & $\begin{array}{l}\text { interferon stimulated exonuclease } \\
\text { gene }\end{array}$ & 0.95 & $3.70 \times 10^{-7}$ & -2.9 & 0.0077 & -2.4 & 0.0036 \\
\hline 218995_s_at & EDNI & 1906 & endothelin I & 0.94 & $3.16 \times 10^{-7}$ & -2.2 & 0.0333 & -2.7 & 0.0014 \\
\hline 219045_at & RHOF & 54509 & ras homolog gene family, member $F$ & 0.93 & $4.81 \times 10^{-7}$ & -2.9 & 0.0062 & -2.0 & 0.0018 \\
\hline 214774_x_at & TNRC9 & 27324 & trinucleotide repeat containing 9 & 0.93 & $4.39 \times 10^{-7}$ & -2.9 & 0.0109 & -3.9 & 0.0027 \\
\hline 20629I_at & NTS & 4922 & neurotensin & 0.93 & $6.81 \times 10^{-8}$ & -102 & 0.0009 & -17.9 & 0.0011 \\
\hline 201909_at & RPS4YI & 6192 & ribosomal protein S4, Y-linked I & 0.92 & $3.55 \times 10^{-8}$ & -5.8 & $0.007 I$ & -18.8 & 0.0000 \\
\hline 206700_s_at & JARIDID & 8284 & $\begin{array}{l}\text { jumonji, AT rich interactive domain } \\
\text { ID }\end{array}$ & 0.90 & $2.41 \times 10^{-7}$ & -2.3 & 0.0366 & -4.0 & 0.0000 \\
\hline 203043_at & ZBEDI & 9189 & zinc finger, BED-type containing I & 0.90 & $6.01 \times 10^{-6}$ & -1.7 & 0.0427 & -1.9 & 0.0026 \\
\hline 202499_s_at & $S L C 2 A 3$ & 6515 & solute carrier family 2 , member 3 & 0.90 & $2.86 \times 10^{-6}$ & -1.9 & 0.0128 & -2.3 & 0.0073 \\
\hline 216623_x_at & TNRC9 & 27324 & trinucleotide repeat containing 9 & 0.90 & $5.79 \times 10^{-7}$ & -2.6 & 0.0128 & -3.5 & 0.0038 \\
\hline
\end{tabular}

aProportion of variance in gene expression due to mtDNA status in cultured cells and xenografts bBayes modified $\mathrm{F}$ test (multiple hypothesis corrected)

'Fold-change

dBenjamini and Hochberg corrected two-tailed Student's t-test 
xenograft models, respectively. Tumor volume was calculated using the equation $\mathrm{V}\left(\mathrm{mm}^{3}\right)=\mathrm{a} \times \mathrm{b}^{2} / 2$, where $\mathrm{a}$ is the largest diameter and $b$ is the smallest diameter. No significant body weight loss was observed. To perform gene expression profiling, tumors (4 tumors per group) were harvested and snap frozen immediately on dry ice when the tumor size reached $500-800 \mathrm{~mm}^{3}$. Tumor tissue was dissected, homogenized in Trizol, and total RNA was isolated and subjected to gene expression analysis as described above.

\section{Additional Files}

Additional information about the data reported in this manuscript, including formatted gene expression data in these studies are available at BMC Genomics.

\section{Results and discussion Establishment of A549 $\rho^{0}$ cell cultures}

Candidate A549 $\rho^{0}$ lung cancer cell cultures were prepared using previously described ethidium bromide-based protocols [12]. Consistent with prior reports of $\rho^{0}$ cell lines (e.g. $[7,9,33])$, the resulting cells displayed auxotrophic growth dependence on pyruvate and uridine and elongated shape (data not shown). The growth rate of the candidate $\rho^{0}$ cells ( 27 hour generation time) was slower than the parental line (20 hour generation time) in pyruvate and uridine supplemented medium (Fig. 1A).

We used the recently described pseudo-gene ratioing technique to estimate the amount of $\mathrm{mtDNA}$ remaining in the candidate A549 $\rho^{0}$ cell cultures (Methods) [21]. This technique is based on quantifying the relative co-amplification of a mtDNA sequence and a nuclear-embedded mitochondrial pseudogene $(\mathrm{mtDNA} \psi)$ sequence [22] using total DNA extracted from candidate A549 $\rho^{0}$ cells and parental A549 cells. Assuming the mtDNA $\psi$ sequence is present in two copies per candidate A549 $\rho^{0}$ cell, we could estimate with $95 \%$ confidence that the candidate A549 $\rho^{0}$ cell cultures contained less than one copy of mtDNA per 14 cells. As a positive control, we used the same technique to estimate that a minimum of 45 mtDNA copies were extracted from each parental A549 cell (exact binomial upper 95\% confidence limit). As a consequence of these observations, as well other biochemical characterizations described below, we will hereafter refer to the candidate A549 $\rho^{0}$ cell cultures as A549 $\rho^{0}$ cells.

\section{Cultured A549 $\rho^{0}$ cells have impaired rates of oxygen consumption}

To characterize mitochondrial function in the parental A549 and A549 $\rho^{0}$ cells, we compared their rates of oxygen consumption. As expected, parental A549 cells showed robust oxygen consumption while the oxygen consumption of the A549 $\rho^{0}$ cells was indistinguishable $(P=0.41)$ from background (Fig. 1B). To demonstrate the involvement of respiration, we also treated parental A549 and A549 $\rho^{0}$ cells with antimycin A, an inhibitor of mitochondrial complex III of the electron transport chain (ETC) [34], prior to measuring oxygen consumption. As expected, antimycin A-treated A549 cells showed reduced oxygen consumption, while A549 $\rho^{0}$ cells were not significantly affected by drug-treatment (Fig. 1B). These results strongly suggest that residual mitochondria-dependent aerobic respiration in A549 $\rho^{0}$ cells, if present, is below the threshold that can be measured in this assay.

\section{A549 $\rho^{0}$ cells grow in tumor xenografts at a slower rate than their parental cells}

Parental A549 cells and their $\rho^{0}$ derivatives both grew as xenografts when implanted shallowly (subcutaneously/ intramuscularly) in the flank muscle of nude mice. mtDNA-depleted cell lines have been reported to form xenograft tumors $[13,18,19]$. Here, we found that A549 $\rho^{0}$ cells grow readily in xenograft, although at a slower rate and after a longer induction period (approximately 30 days) relative to the parental line (Fig. 2). This is consistent with the growth characteristics of tumor xenografts derived from N2B $\rho^{0}$ osteosarcoma [18], E3 $\rho^{0}$ serous ovarian carcinoma [18], HSA $\rho^{0}$ cervical cancer [18], and T47D $\rho^{0}$ breast cancer [19] cell lines relative to their parental counterparts.

\section{A549 $\rho^{0}$ cells do not express mtDNA-derived transcripts in culture or in xenografts}

We performed quantitative PCR analysis of mtDNAencoded MT-ATP6 and MT-CYB transcripts in A549 and A549 $\rho^{0}$ cells grown in culture and in xenografts, in the absence of ethidium bromide. In contrast to the parental A549 cells, the expression of these two transcripts could not be detected in $\rho^{0}$ cells (Additional File 1). This strongly suggests that, in bulk, the A549 $\rho^{0}$ cells retained their mtDNA-depleted genotype over the course of their growth in culture and in xenograft. This was important to ascertain since it was possible that during their growth in xenograft, rare mtDNA-positive cells present in the injected A549 $\rho^{0}$ cell population could have substantially increased in abundance and affected our downstream analyses. Similarly, it is possible that A549 or A549 $\rho^{0}$ cells with certain genetic or epigenetic changes (e.g. those that confer a growth advantage) were selected for in culture or in xenografts and affected our results. This should be considered when interpreting the molecular analyses discussed below.

\section{Gene expression profiling of cultured cells}

Gene expression profiles were generated in plateau phase A549 and A549 $\rho^{0}$ cells cultured in fresh medium supplemented with pyruvate and uridine prior to RNA isolation (see Additional File 2 for all data and Additional File 3 for 
A

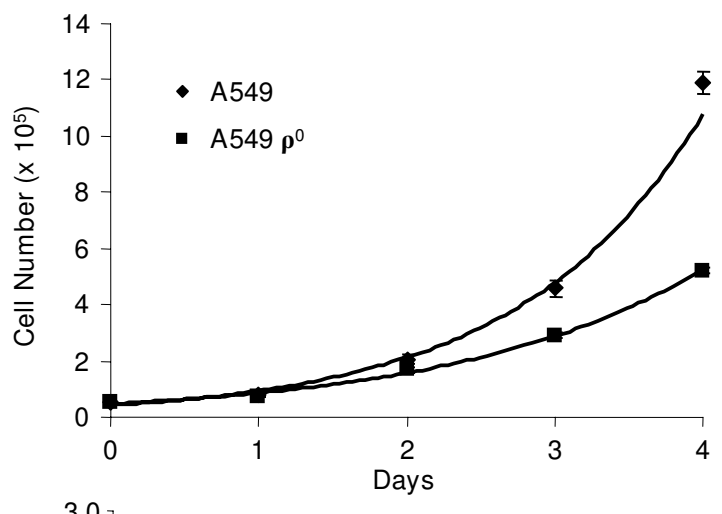

B

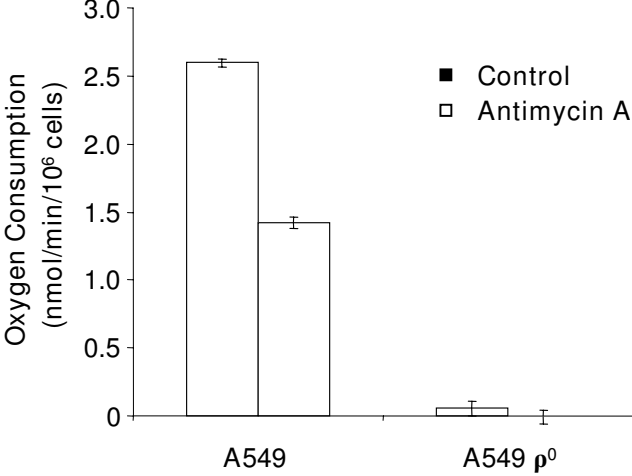

Figure I

Characterization of cultured A549 and A549 $\rho^{0}$ cells. (A) Growth rates of A549 and A549 $\rho^{0}$ cells in culture are provided. Experiments were run in triplicate with error bars representing \pm I standard deviation. Doubling times obtained from the fitted curves $\left(\mathrm{N}=\mathrm{N}_{0} \mathrm{e}^{\mathrm{rt}}\right)$ were 20.4 and 27.3 hours for parental A549 and A549 $\rho^{0}$ cultures, respectively. (B) The oxygen consumption of A549 and A549 $\rho^{0}$ cultured cells is provided. Where indicated, cells were treated with I $\mu \mathrm{g} / \mathrm{mL}$ antimycin $\mathrm{A}$, an inhibitor of the mitochondrial electron transport chain (ETC). Experiments were run in triplicate with error bars representing \pm I standard deviation.

volcano plot). All 276 transcripts that were differentially expressed (defined for every pair-wise comparison discussed hereafter as being $>1.5$-fold change, two-tailed Student's t-test $P<0.01$ (subjected to Benjamini and Hochberg correction for multiple comparisons), and $>20$ unit difference in geometric mean expression scores) are listed in Additional File 4. These include 131 transcripts that were more highly expressed in A549 $\rho^{0}$ cells and 145 that were more highly expressed in A549 cells.

\section{Increased levels of EMT-related transcripts in cultured A549 $\rho^{0}$ cells}

To analyze differentially expressed genes in A549 cells and their mtDNA-depleted $\rho^{0}$ counterparts, we conducted
Gene Ontology (GO) analyses on transcripts that were more highly expressed in the A549 $\rho^{0}$ cells than the parental cell line (see Additional File 5A for transcript names and Additional File 2 for data analysis of specific transcript). We used stringent criteria (Fisher's exact test $P<$ 0.001 and at least 4 transcripts) for selection of enriched categories. The enriched categories included those related to cell adhesion (15 transcripts) and cell motility (4 transcripts). Upon further inspection of the transcripts in these categories, it became apparent that they reflect transcriptional signatures of the epithelial-mesenchymal transition (EMT), a developmental process by which stationary epithelial cells transform into mobile mesenchymal cells [35]. EMT can be driven by the activity of the transcription factor $S N A I 2$, positively regulated by $L O X L 2$ [36], which leads to the over-expression of $\mathrm{CDH} 2$, ITGB3, and VIM. All five genes are over-expressed in the $\rho^{0}$ cells. The fact that $C D H 1$ and FGA are also less abundant in the $\rho^{0}$ cells further supports the hypothesis that the $\rho^{0}$ cells show an increasingly mesenchymal phenotype relative to their parental counterparts [35]. The above observations are consistent with prior reports of mtDNA-depleted A549 cells showing increased invasive behavior relative to parental A549 cells in a Matrigel basement membrane matrix invasion assay system [12].

\section{Increased metal ion binding and glucuronidation gene expression in A549 $\rho^{0}$ cell cultures}

Two enriched GO categories were related to metal ion binding (LOXL2 and metallothionein family members MT1H, MT1G, MT1X, and MT2A) and glucuronidation (including UDP glucuronosyltransferase 1 family members). The increased expression of MTF-1 regulated genes (i.e. metallothioneins) could indicate higher baseline levels of oxidative stress and/or free metals in the $\rho^{0}$ cells relative to their parental counterparts [25]. However, it is noteworthy that several oxidative stress response genes (e.g. GPX2, GPX3, and GLRX) are under-expressed in these $\rho^{0}$ cells. Glucuronidation is a cellular metabolic pathway in which UDP-glucuronosyltransferases (UGTs) convert lipophilic compounds, both endogenous and xenobiotic, into more readily excreted polar products. UGTs catalyze the transfer of the glucuronate moiety of uridine diphosphoglucuronate (UDPGA) to specific substrates, in order to attain this increased polarity. The observed differentially expressed UGT1A family members have different substrate specificities and collectively can react with a variety of endogenous lipophilic molecules, such as fatty acids and steroids [37-41]. Given that $\rho^{0}$ skin fibroblasts have impaired mitochondrial fatty acid $\beta$-oxidation [42], we propose that the increased abundance of glucuronidation-related transcripts in A549 $\rho^{0}$ cells is a survival mechanism to remove excess fatty acids that are normally metabolized to carbon dioxide and water in functional mitochondria. 


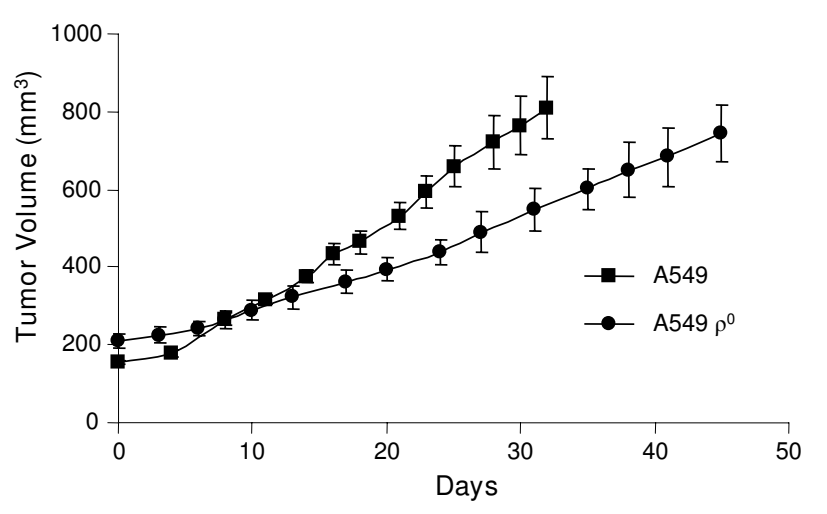

Figure 2

Growth rates of A549 and A549 $\rho^{0}$ xenografts. Median tumor volume over time in nude mice bearing tumors derived from A549 or A549 $\rho^{0}$ cells. Tumor volume measurements commenced at an initial average tumor volume of $155 \mathrm{~mm}^{3}$ and $208 \mathrm{~mm}^{3}$, respectively. Experiments were conducted using six or seven mice per cohort with error bars representing \pm I standard error of the mean (SEM).

\section{Expression profiles of HIF-I responsive transcripts in A549 $\rho^{0}$ cells}

Next, we focused on identifying key transcription factors that could account for a significant number of overexpressed transcripts in A549 $\rho^{0}$ cells. mtDNA-deficient cells have proven useful for dissecting the role that mitochondria play in HIF-mediated responses to oxygen levels (reviewed by [43]). In fact, increased baseline levels of HIF-1 activity in cultured $\rho^{0}$ cell lines have been noted by others $[44,45]$. In our A549 $\rho^{0}$ cells, HIF-1 appeared to be an excellent candidate given the over-expression of two well-established downstream genes (VEGFA and BNIP3). We began our analyses by focusing on a group of 95 probe sets representing 63 unique HIF-1 responsive genes highlighted in a recent comprehensive review [46] (Additional File 6). While no other HIF-1 responsive genes reached our statistical criteria for over-expression, four other wellestablished HIF-1 regulated transcripts (IGFBP1, IGFBP3, $T F$, and PTGS2) were less abundant in the $\rho^{0}$ cells relative to their parental cells. This could reflect the influence of other transcription factors or accessory proteins that regulate HIF-1 activity.

The mechanism underlying the differential expression of HIF-regulated transcripts in mtDNA-deficient cells is unknown. For example, it has been proposed that a feedback loop involving mitochondrial enzymes and citric acid cycle intermediates leads to HIF-1 stabilization and tumorigenesis in several inherited forms of cancer caused by mtDNA mutations [47]. Another possible explanation might involve insulin-like growth factor signaling which has been shown to increase HIF-1 levels [48]. Importantly, the GO category insulin-like growth factor binding (CYR61, HTRA1 aka PRSS11, IGFBP4, and IGFBP7) was enriched for transcripts that were more abundant in the $\rho^{0}$ relative to parental cells (Additional File 5A).

\section{A549 $\rho^{0}$ cells over-express HIF-I a protein relative to the parental cell line}

To explore the mechanistic basis for the observed differential expression of HIF-responsive transcripts in culture, we measured the levels of HIF- $1 \alpha$ protein in $\rho^{0}$ and parental cells by ELISA (Fig. 3A). The background levels of HIF-1 $\alpha$ were found to be 3 -fold higher in $\rho^{0}$ cells compared to the parental line. HIF- $1 \alpha$ levels increased in the parental A549 line following treatment with cobalt acetate or incubation under hypoxic $\left(1.5 \% \mathrm{O}_{2}\right)$ conditions. In A549 $\rho^{0}$ cells, HIF- $1 \alpha$ levels were increased modestly following cobalt treatment but did not appear to be changed by hypoxic treatment. However, the level of HIF- $1 \alpha$ protein does not solely determine its ability to induce gene expression, as post-transcriptional modifications are also known to modulate its activity [49].

To further explore the possible functional consequences of HIF-1 over-expression, we measured the levels of several HIF-regulated gene products by Western blot (Fig. 3B). The MT-CO2 product was included in this analysis to demonstrate the absence of this mtDNA-encoded protein in A549 $\rho^{0}$ cells. In accordance with the expression data, we found that PGK1 and DDIT4 protein levels were increased in A549 $\rho^{0}$ cells (Fig. 3B). However, GLUT1 (aka SLC2A1) protein levels were essentially unchanged in A549 and A549 $\rho^{0}$ cells despite the fact that its transcript was 2.0-fold more abundant (corrected $P=0.017$ ) in A549 $\rho^{0}$ cells. As could be expected, the incubation of either parental or $\rho^{0}$ cells in the presence of cobalt or under hypoxic conditions led to increased levels of these HIF-regulated proteins. The effect of cobalt was not as significant as that of hypoxia under these conditions. These data demonstrate that although baseline HIF-1 activity is higher in $\rho^{0}$ than parental cells, HIF-regulated activity can be induced further in both cases.

\section{Decreased icosanoid metabolism and cytoskeleton gene expression in cultured $\mathbf{A 5 4 9} \rho^{0}$ cells}

In parallel, we conducted separate GO analyses on transcripts that were less abundant in A549 $\rho^{0}$ cells $(P<0.001$ and at least four probes sets) (Additional File $5 \mathrm{~B}$ ). The blood pressure regulation (FGB, PTGS2, FGG, and FGA) and icosanoid metabolism (AKR1C2, PLA2G4A, PTGS2, and MGST2) GO categories were significantly enriched for such transcripts. The presence of multiple fibrinogen family members in the former category could reflect possible differences in cell adhesion in $\rho^{0}$ cells. The icosanoid metabolism category could relate to the role arachidonic 
acid plays in the regulation of steroidogenesis and mitochondrial membrane permeability. It has been proposed that ATP generated by oxidative phosphorylation plays a key role in the generation and export of arachidonic acid from the mitochondria [50]. Through its role in leukotriene metabolism, arachidonic acid mediates the activity of steroidogenic acute regulatory protein (StAR), a key regulator of steroidogenesis. In addition, arachidonic acid can uncouple oxidative phosphorylation and alter mitochondrial membrane permeability [51].

The intermediate filament GO category was enriched for transcripts that were less abundant in $\rho^{0}$ cells (i.e. KRT8, KRT19, NEFL, KRT18, and DSP). KRT18 plays a key role in maintaining the normal morphology of mitochondria [52]. Interestingly, VIM, another component of intermediate filaments shown to support mitochondrial morphology and organization [53], is over-expressed in $\rho^{0}$ cells. The dysregulation of intermediate filament genes in $\rho^{0}$ cells could contribute to their aberrant mitochondrial morphology and/or represent cellular responses to rescue mitochondrial organization.

\section{Increased tRNA synthetase, MHC Class I, and lysosome gene expression in $A 549 \rho^{0}$ xenografts}

Total RNA from A549 or A549 $\rho^{0}$ tumors (four per cohort) were also subject to gene expression profiling analysis (see Additional File 3 for volcano plot). All 948 transcripts that were differentially expressed are listed in Additional File 7. These include 485 transcripts that were more highly expressed in the A549 $\rho^{0}$ tumors and 463 that were more highly expressed in A549 tumors. Three major functional categories emerged from GO analyses of over-expressed genes in $\rho^{0}$ xenografts (Additional File 8A). These categories were related to tRNA aminoacylation (composed of 9 tRNA synthetases), MHC class I (B2M, MR1, and six HLA gene family members), and the lysosome (23 transcripts).

The transcriptional induction of tRNA synthetases was previously highlighted in the analysis of cultured $\rho^{0}$ and parental lymphoblasts [44]. Recently, there is increased evidence that tRNA synthetases have functions additional to joining specific amino acids to their cognate tRNAs. These include the regulation of angiogenesis and inflammation $[54,55]$.

The over-expression of MHC Class I peptides is consistent with a report that MHC I is over-expressed in fibroblasts from patients with mtDNA defects as well as in cultured osteosarcoma $\rho^{0}$ cells relative to their parental counterparts [56]. In that study, IFN- $\gamma$ treatment enhanced MHC1 over-expression in cultured osteosarcoma $\rho^{0}$ cells. Thus, the over-expression of interferon gamma receptor 1 (INFGR1) we observed in A549 $\rho^{0}$ xenografts (1.8-fold, corrected $P=0.004$ ) could play a role in further stimulating MHC Class I peptide expression in these cells.

It has been proposed that MHC Class I over-expression in cells with mutated mitochondrial proteins provides a mechanism by which the immune system can recognize and eliminate defective cells [56]. Although $\rho^{0}$ cells do not have dysfunctional proteins encoded by mtDNA, the over-expression of MHC Class I genes may simply reflect a mechanism for marking cells with defective mitochondrial function.

The over-expression of lysosome genes could relate to their function in removing defective mitochondria within cells through autophagy [57]. This could complement the immune surveillance mediated removal of cells with defective mitochondria discussed above. We speculate that the over-expression of lysosome-related genes could reflect increased numbers of lysosomes and/or simply the increased functional activity of existing lysosomes.

\section{A549 $\rho^{0}$ xenograft transcriptomes indicate decreased cell proliferation and glycolysis}

Mitosis (21 transcripts) and spindle organization and biogenesis ( 9 transcripts) were two major functional categories showing enrichment for down-regulated transcripts in A549 $\rho^{0}$ xenografts (Additional File $8 B$ ). This would be expected given the lower proliferation rate of the A549 $\rho^{0}$ cells relative to their parental counterparts (Fig. 1A). The enrichment in the actin binding (21 transcripts) and cytoskeleton protein binding (27 transcripts) categories could also reflect differences in growth rates. Alternatively, they could relate to altered mitochondrial morphology, as discussed in our analysis of cultured $\rho^{0}$ cells.

Surprisingly, A549 $\rho^{0}$ xenografts showed decreased expression in the glycolysis category (nine transcripts). This would appear to be counter-intuitive given the fact that these xenografts do not express mtDNA-derived transcripts (Additional File 1) or MT-COX2 protein (Fig. 3B) and thus should have severely impaired oxidative phosphorylation. Indeed, the 4.7-fold increased abundance of PCK2 in A549 $\rho^{0}$ cells could indicate higher levels of gluconeogenesis, consistent with prior reports in mtDNAdepleted A549 [12], 206B $\rho^{0}$ osteosarcoma [58], and ARPE19 $\rho^{0}$ retinal pigment epithelial [58] cultured cells. Apart from the aforementioned lower growth rate of $\rho^{0}$ xenografts, this probably reflects the general reduced abundance of HIF-regulated transcripts (GAPDH, PKM2, ENO2, LDHA, EGLN1, SLC2A1, TF, P4HA1, IGF2, CA9, HIG2, ADM, and EGLN3) as compared to the parental A549 xenografts (Additional File 6). This occurs despite the fact that HIF-1 $\alpha$ is over-expressed (2.6-fold, $P=1.6 \times$ $10^{-4}$ ) along with two other well-established HIF targets (HK1 and BHLHB3). As discussed earlier, this is consistent 

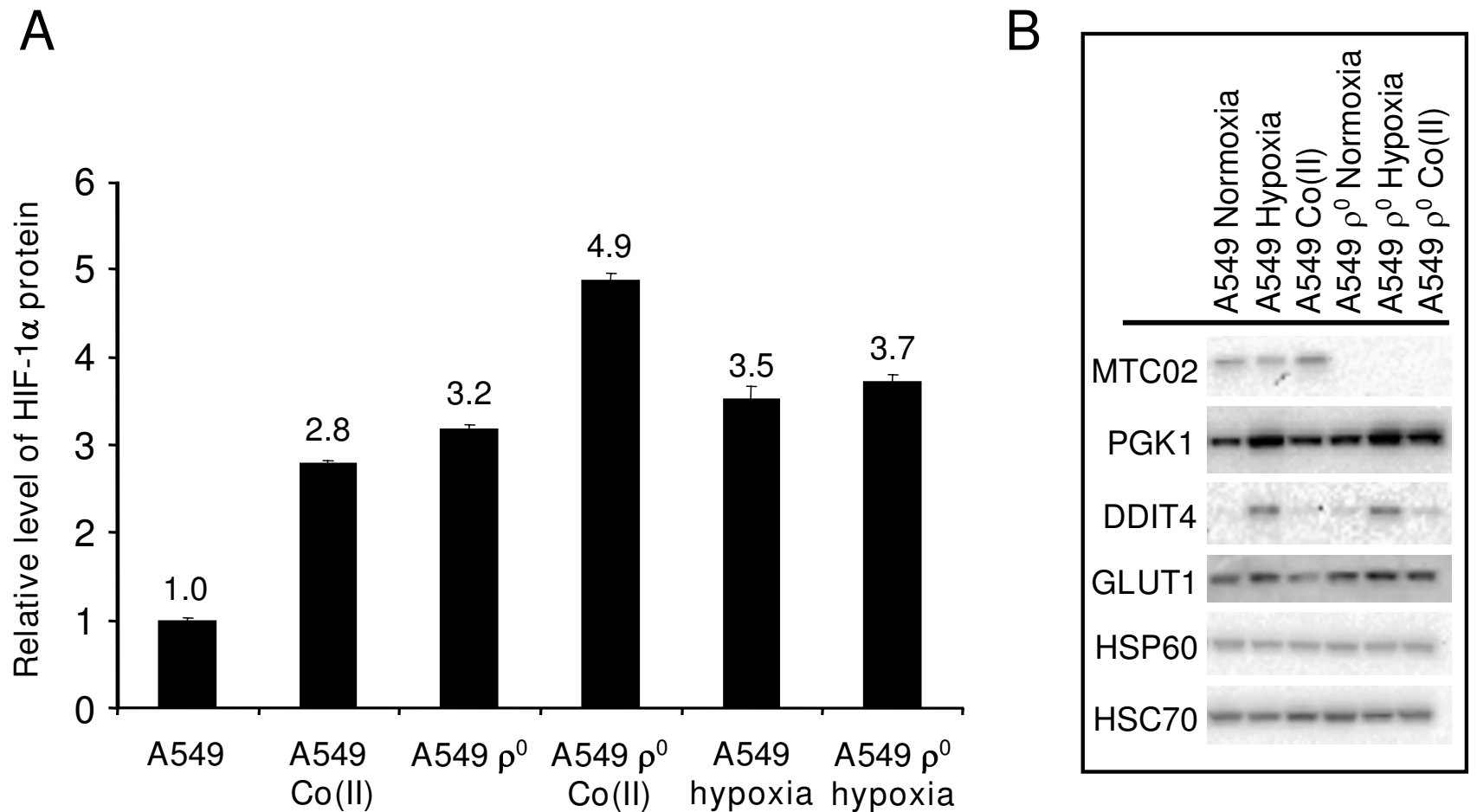

Figure 3

Levels of HIF-I $\alpha$ and HIF-I target proteins in A549 and A549 $\rho^{0}$ cells. Plateau phase cultures were treated with control vehicle (mannitol), cobalt acetate (cobalt, I00 $\mu \mathrm{M}$ ), or hypoxia (I.5\% oxygen atmosphere). (A) Levels of HIF-I $\alpha$ protein relative to control vehicle after 4 hours treatment as measured by ELISA. Effect of incubation under hypoxic conditions or with cobalt acetate is shown for comparison. Error bars indicate one standard deviation. (B) Representative Western blot showing MT-CO2, PGKI, DDIT4, GLUTI, and HSP60 levels in A549 and A549 $\rho^{0}$ cells. PGKI and DDIT4 levels were more abundant (I.4- and 4.0-fold, respectively) in A549 $\rho^{0}$ cells relative to A549 cells. In contrast, GLUTI and HSP60 levels were only marginally changed (I.I- and I.25-fold less abundant) in A549 $\rho^{0}$ cells relative to A549 cells. All estimates were made via phorphorimaging analysis with HSC70 levels serving as a loading control. Note that MT-CO2 levels could not be detected in any A549 $\rho^{0}$ experiment while DDIT4 was expressed at low levels, but could be quantified in normoxic cells.

with the post-translational control of HIF-1 $\alpha$ activity (protein modification or subunit localization) and/or the activity of other transcription factors.

\section{Contribution of mtDNA to gene expression profiles of cultured cells and xenografts}

While gene expression differences between A549 cells grown in culture and in xenograft have been reported [59], comparison for both parental and mtDNA-deficient cells have not been previously performed. Interestingly, a greater number of transcripts were differentially expressed due to growth conditions (culture versus xenograft) than by mtDNA status. Importantly, infiltrating mouse cells have been demonstrated not to influence significantly gene expression profiles of tumor xenografts when using similar Affymetrix human microarrays [59]. All 2,512 transcripts that were differentially expressed in xenograft versus culture for the parental A549 line are listed in Additional File 9. The 2,108 differentially expressed transcripts for the A549 $\rho^{0}$ cells grown in xenograft versus culture are listed in Additional File 10 (see Additional File 3 for volcano plot). These results are borne out by hierarchical clustering analysis which first shows a clear separation of the gene expression profiles grown in culture versus xenograft and then separation according to mtDNA status, based on gene expression data obtained from 538 probe sets whose coefficient of variation was greater than 0.10 (Fig. 4).

We calculated the relative fraction of the variance associated with mtDNA status in the gene expression profiles from A549 $\rho 0$ and parental A549 cells grown in culture and in xenografts (Additional File 2). In particular, we focused on those transcripts for which over $50 \%$ of the 
variance (Benjamini and Hochberg corrected Bayes moderated $\mathrm{F}$ test $\mathrm{P}<0.01$ ) could be explained by mtDNA status and where there was significant differential expression in any two of the pair-wise comparisons of A549 $\rho 0$ and parental A549 cells grown in culture or in xenograft. Overall, we discovered 430 transcripts (229 up-regulated and 201 down-regulated in A549 $\rho 0$ relative to the parental A549 cells) that met these criteria (Additional File 11). Table 1 provides a listing of a subset of these transcripts where at least $90 \%$ of the variance in gene expression was dependent upon mtDNA status.

Importantly, the probe set that was most strongly affected (in this case down-regulated) by mtDNA status measures the relative abundance of MT-ND5, the only mtDNAencoded transcript represented in this microarray (Table 1). MT-ND5 is not expressed in the A549 $\rho^{0}$ cells in culture or in xenograft (i.e. ranking within the lowest $15^{\text {th }}$ percentile of all median gene expression scores in both cases). This provided us with empirical proof that our sorting strategy was sensitive to detecting transcripts dependent upon mtDNA status. Overall, we found that the variance in the expression of transcripts within MHC-1 (6 transcripts) and glucuronidation (4 transcripts) GO categories are all highly dependent upon mtDNA status (Fig. 5). These transcripts were more abundant in A549 $\rho^{0}$ relative to the parental A549 cells. The MHC-1 and glucuronosyltransferase categories were previously discussed as having significance for the immune surveillance of cells with effective mitochondria and the detoxification of lipids that can accumulate due to defects in fatty acid metabolism. On the other hand, transcripts related to the protein complex assembly ( 11 transcripts) and chromatin ( 7 transcripts) GO categories were highly dependent upon mtDNA status and less abundant in A549 $\rho^{0}$ cells relative to the parental A549 cells (Additional File 12). This could reflect their slower growth rates relative to the parental cell line.

In addition, mtDNA status affected multiple transcripts related to the above discussed epithelial-mesenchymal transition (EMT). Over 50\% of the variance in the expression levels derived from probe sets for the previously described SNAI2, ITGB3, CDH1, and FGA genes could be explained by mtDNA status. The expression levels of all these genes indicated A549 $\rho^{0}$ cells have increased mesenchymal phenotypes relative to the parental A549 cells. However, the fold-changes in expression of these genes in $\rho^{0}$ versus parental cells were greater in culture than in the tumor xenografts (Additional File 2).

In contrast to genome-wide expression studies performed in yeast lacking mtDNA ( $\rho^{0}$ petites), we observed no evidence for a strong dependence of the variance in peroxisomal gene expression (especially based on 26 probe sets for peroxin (PEX) genes responsible for peroxisome assembly) due to mtDNA status [60]. Nevertheless, this does not preclude mtDNA status affecting peroxisome function, through abundance and/or activity. For example, we observed that the mtDNA status had a significant effect on $P H Y H$ expression (explains $76 \%$ of the observed variance in expression, F-test $\left.P=4.56 \times 10^{-4}\right)$. $P H Y H$ encodes a peroxisomal enzyme critical for the catabolism of phytanic acid, a branched chain fatty acid $[61,62]$. AMACR, which also encodes an enzyme critical for phytanic acid metabolism, is also expressed higher in A549 $\rho^{0}$ xenografts relative to A549 xenografts (2.0-fold, corrected $P=0.007$ ). Interestingly, AMACR, which localizes to both peroxisomes and mitochondria, is an emerging biomarker for prostate cancer [63]. Given reports of frequent mitochondrial defects in prostate cancer [64], it is tempting to speculate that the over-expression of AMACR in prostate cancer could be related to defective mitochondrial function. However, it should be emphasized that the mitochondrial defects in our mtDNA-depleted A549 system will be more severe than those found in human tumors.

\section{mtDNA-dependent expression profiles show agreement with prior reports}

It can be questioned whether the observed mtDNAdependent gene expression profiles are (i) shared amongst all cell lines, (ii) unique to our system, or (iii) reflect possible mutations in acquired in the nuclear genome of the ethidium bromide-treated A549 $\rho^{0}$ cells. To begin to address these issues, we searched for previous reports of differential gene expression in cultured $\rho^{0}$ cells relative to their parental cell lines. It is important to note that there is a limited literature on gene expression profiling in mtDNA-depleted cell cultures $[16,44,65,66]$ and that there are no previous reports of gene expression profiling in mtDNA-depleted xenografts. Nevertheless, we found confirmatory evidence for our observed major categories of mtDNA-dependent transcripts levels including: tRNA synthetases (over-expressed in osteosarcoma $\rho^{0}$ cells [66] and lymphoblastoid $\rho^{0}$ cells [44]), MHC-related transcript (over-expressed in osteosarcoma $\rho^{0}$ cells [56] and breast cancer $\rho^{0}$ cells [65]), UDP-glucuronosyltransferase (over-expressed in breast cancer $\rho^{0}$ cells [65]), and HIF1- $\alpha$ (over-expressed in lymphoblastoid $\rho^{0}$ cells [44]). Furthermore, the FXY2D2 (aka ATP1G1) and the VLDR transcripts, whose levels were strongly dependent upon mtDNA-status and over-abundant in A549 $\rho^{0}$ cells (Table 1 ), were found to be over-expressed in human fibroblasts with mutations in nuclear-encoded mitochondrial Complex I genes [67] and retinal pigment epithelial $\rho^{0}$ cells [14], respectively. Similarly, metallothionein transcripts were over-expressed in fibroblasts containing mutated nuclear-encoded mitochondrial genes, in agreement with our observations in A549 $\rho^{0}$ cell cultures [67]. Thus, results from multiple laboratories testing different $\rho^{0}$ cell 
cultures support the assertion that our current analyses at least partially reflect mtDNA-dependent gene expression relevant to multiple cell types. Future gene expression profiling experiments of mtDNA-depleted cells generated using non-chemical-based protocols, such as expressing siRNA against the TFAM gene [68] or a dominant negative form of the mitochondria-specific DNA polymerasegamma [69], could provide valuable empirical data to assess our candidate mtDNA-dependent gene expression profiles. Ultimately, large-scale proteomic characterization of mtDNA-depleted and parental cells will be necessary to rigorously assess possible functional consequences of differential gene expression $[15,70]$.

\section{Contribution of growth conditions to gene expression profiles}

Next, we calculated the relative fraction of the variance associated with growth conditions in the gene expression profiles from $\rho^{0}$ and parental cells grown in culture and in xenografts. At first, we focused on those transcripts for which over $50 \%$ of the variance (corrected F test $P<0.01$ ) could be explained by growth conditions and where there was differential expression in any of the pair-wise comparisons of $\rho^{0}$ and parental A549 cells grown in culture or in xenograft. Overall, we uncovered 2,633 transcripts that met these criteria. In order to reduce transcript complexity, we focused on the subset of 551 transcripts (316 upregulated and 235 down-regulated in xenografts relative
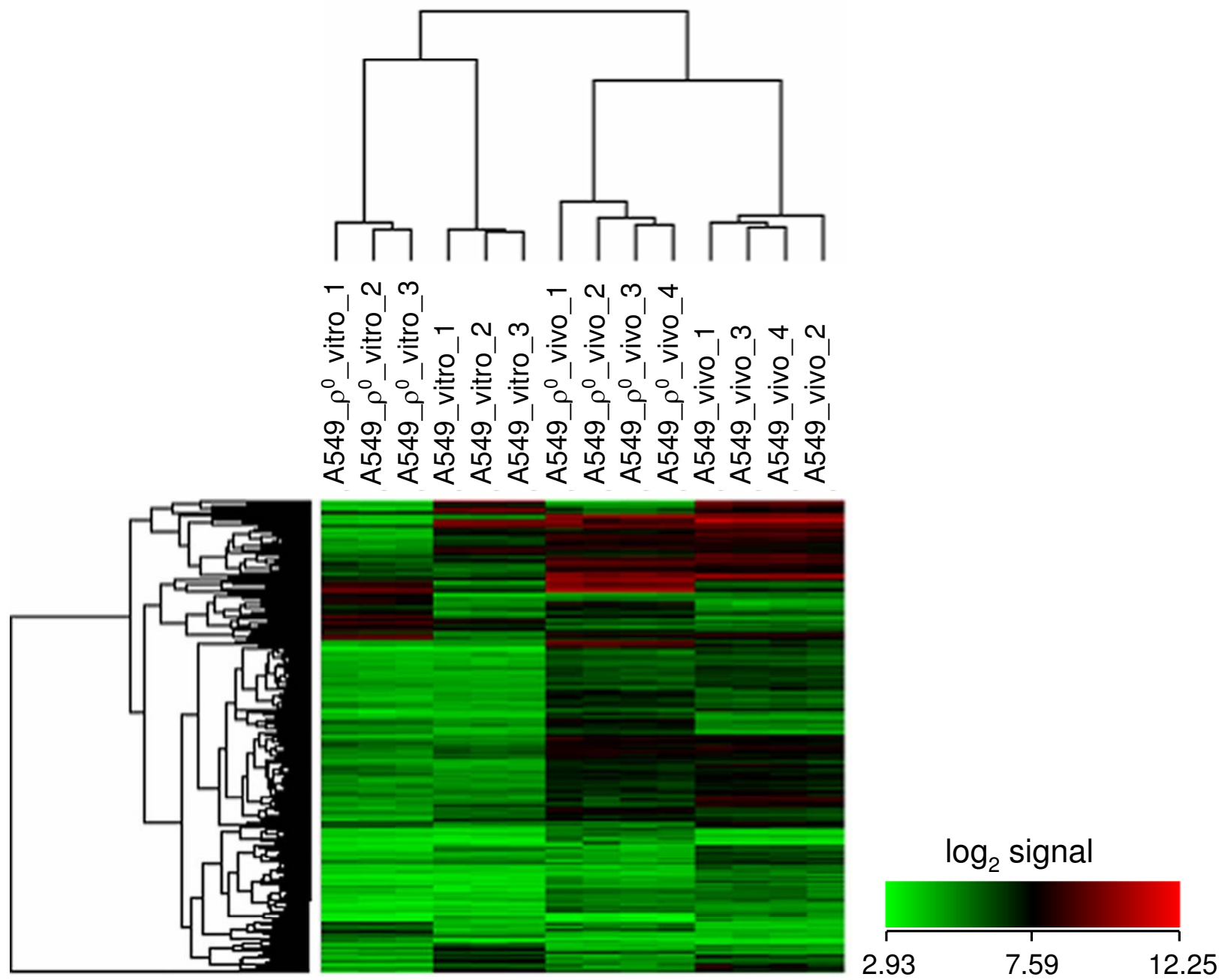

\section{Figure 4}

Hierarchical clustering analysis of expression data from A549 and A549 $\rho^{0}$ cells in culture and in xenografts. The dendrograms were generated based on average linkage hierarchical clustering of expression data from 538 probe sets whose coefficient of variation was greater than 0.10. Data from A549 cultures are provided in triplicate. 
to cultured cells) where growth conditions contributed to a robust $90 \%$ of the variance observed in the data set (Additional File 13). Table 2 lists a subset of these transcripts where at least $97 \%$ of the variance in gene expression was dependent upon mtDNA status.

Of the GO categories enriched for transcripts whose expression was highly dependent upon growth conditions, only the nuclear RNA splicing GO category (9 tran- scripts) were more abundant in xenografts relative to cultured cells (Additional File 14A). However, multiple GO categories were enriched for transcripts whose variance was principally explained by growth conditions and were less abundant in xenografts relative to cell culture. These included categories related to mitochondrial function (50 mitochondrion transcripts), glycolysis (7 transcripts), electron carrier activity (11 transcripts), purine

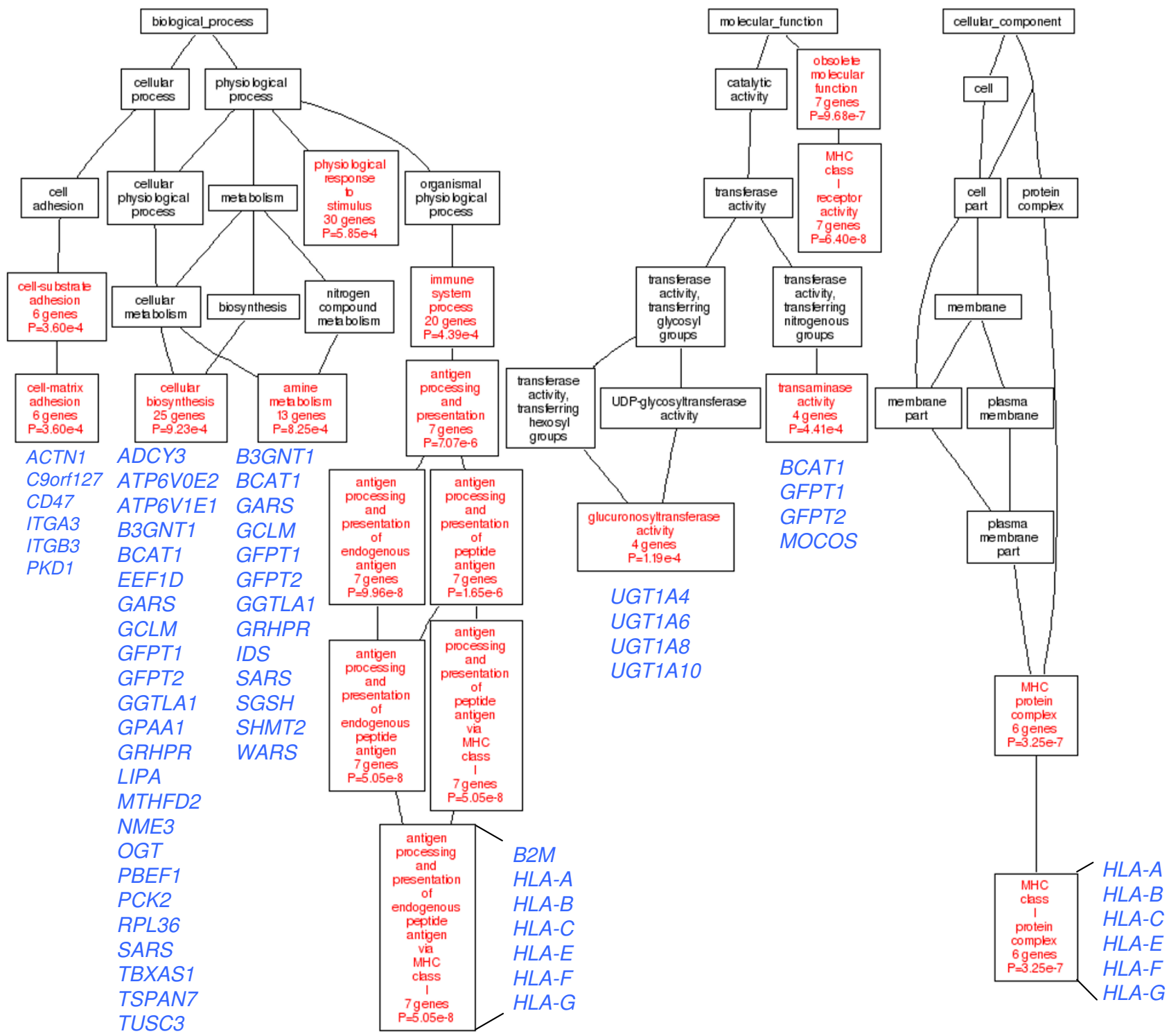

Figure 5

Gene Ontology analysis of up-regulated transcripts in $\rho^{0}$ cells whose variance is strongly influenced by mtDNA status. The directed acyclic graph (DAG) represents the relationships of categories (shown in red) that are enriched for transcripts where mtDNA status accounted for over $50 \%$ of the observed variance in gene expression and are more abundant in vitro (i.e. cell culture) and/or in vivo (i.e. xenograft) in A549 $\rho^{0}$ cells relative to parental A549 cells. All 229 probe sets used in this analysis are provided in Additional File II. The names of genes in terminal categories are provided the blue. 
Table 2: Transcripts where $97 \%$ of the variance in gene expression is explained by growth conditions

\begin{tabular}{|c|c|c|c|c|c|c|c|c|c|c|}
\hline & \multirow[t]{2}{*}{ Affymetrix Probe IDa } & \multirow[t]{2}{*}{ Gene Symbol } & \multirow[t]{2}{*}{ Entrez GenelD } & \multirow[t]{2}{*}{ Gene Description } & \multirow[t]{2}{*}{$\begin{array}{l}\text { Growth Prop. of } \\
\text { Variance }\end{array}$} & \multirow[t]{2}{*}{$\mathrm{F}$ test $^{\mathrm{c}}$} & \multicolumn{2}{|c|}{$\rho^{0}$ Vivo $/ \rho^{0}$ Vitro } & \multicolumn{2}{|c|}{$\begin{array}{l}\text { WT Vivo/WT } \\
\text { Vivo }\end{array}$} \\
\hline & & & & & & & $\mathrm{FC}^{\mathrm{d}}$ & $\mathrm{Pe}$ & $\mathrm{FC}^{\mathrm{d}}$ & $\mathrm{Pe}$ \\
\hline \multirow{25}{*}{$\begin{array}{l}\text { Up-regulated and } \\
\text { dependent on } \\
\text { growth conditions }\end{array}$} & 21157|_s_at & CSPG2 & 1462 & $\begin{array}{l}\text { chondroitin sulfate } \\
\text { proteoglycan } 2\end{array}$ & 0.99 & $1.41 \times 10^{-12}$ & 34.6 & 0.0001 & 19.0 & 0.0002 \\
\hline & 215646_s_at & CSPG2 & 1462 & $\begin{array}{l}\text { chondroitin sulfate } \\
\text { proteoglycan } 2\end{array}$ & 0.99 & $2.52 \times 10^{-12}$ & 33.5 & 0.0003 & 20.3 & 0.0003 \\
\hline & 220952_s_at & PLEKHA5 & 54477 & $\begin{array}{l}\text { PI 3-phosphate-binding } \\
\text { protein-2 }\end{array}$ & 0.99 & $1.79 \times 10^{-11}$ & 6.7 & 0.0003 & 5.6 & 0.0006 \\
\hline & 209090_s_at & SH3GLBI & 51100 & $\begin{array}{l}\text { SH3-domain GRB2-like } \\
\text { endophilin BI }\end{array}$ & 0.99 & $2.86 \times 10^{-10}$ & 3.0 & 0.0015 & 3.1 & 0.0002 \\
\hline & 216405_at & LGALSI & 3956 & $\begin{array}{l}\text { lectin, galactoside-binding, } \\
\text { soluble, I }\end{array}$ & 0.98 & $6.43 \times 10^{-12}$ & 11.5 & 0.0007 & 14.4 & 0.0006 \\
\hline & 212254_s_at & DST & 667 & dystonin & 0.98 & $3.64 \times 10^{-11}$ & 3.9 & 0.0006 & 4.7 & 0.0003 \\
\hline & 201056 at & GOLGBI & 2804 & $\begin{array}{l}\text { golgin } \mathrm{BI} \text {, golgi integral mem. } \\
\text { protein }\end{array}$ & 0.98 & $2.12 \times 10^{-10}$ & 3.3 & 0.0008 & 2.9 & 0.0004 \\
\hline & $221829 s$ at & TNPOI & 3842 & transportin I & 0.98 & $2.86 \times 10^{-10}$ & 4.0 & 0.0012 & 3.9 & 0.0005 \\
\hline & 204619_s_at & CSPG2 & 1462 & $\begin{array}{l}\text { chondroitin sulfate } \\
\text { proteoglycan } 2\end{array}$ & 0.98 & $3.01 \times 10^{-11}$ & 12.2 & 0.0003 & 7.5 & 0.0003 \\
\hline & 205173_x_at & CD58 & 965 & CD58 molecule & 0.98 & $1.70 \times 10^{-10}$ & 3.5 & 0.0014 & 3.7 & 0.0004 \\
\hline & 218901_at & PLSCR4 & 57088 & phospholipid scramblase 4 & 0.98 & $1.32 \times 10^{-9}$ & 3.5 & 0.0009 & 3.8 & 0.0014 \\
\hline & 213229_at & DICERI & 23405 & Dicer I, Dcr-I homolog & 0.97 & $2.18 \times 10^{-10}$ & 6.1 & 0.0009 & 7.0 & 0.0013 \\
\hline & 208772_at & ANKHDI & 404734 & $\begin{array}{l}\text { ankyrin repeat \& } \mathrm{KH} \text { domain } \\
\text { containing I }\end{array}$ & 0.97 & $1.97 \times 10^{-9}$ & 2.5 & 0.0027 & 2.4 & 0.0003 \\
\hline & 221731_x_at & CSPG2 & 1462 & $\begin{array}{l}\text { chondroitin sulfate } \\
\text { proteoglycan } 2\end{array}$ & 0.97 & $4.35 \times 10^{-11}$ & 104.7 & 0.0001 & 30.9 & 0.0002 \\
\hline & 201057_s_at & GOLGBI & 2804 & $\begin{array}{l}\text { golgin } \mathrm{BI} \text {, golgi integral mem. } \\
\text { protein }\end{array}$ & 0.97 & $1.39 \times 10^{-9}$ & 3.2 & 0.0027 & 2.9 & 0.0002 \\
\hline & 214295_at & KIAA0485 & 57235 & KIAA0485 protein & 0.97 & $4.14 \times 10^{-10}$ & 3.9 & 0.0014 & 4.1 & 0.0008 \\
\hline & 201024_x_at & EIF5B & 9669 & $\begin{array}{l}\text { eukaryotic translation } \\
\text { initiation factor } 5 B\end{array}$ & 0.97 & $2.66 \times 10^{-9}$ & 2.3 & 0.0012 & 2.2 & 0.0012 \\
\hline & 201280_s_at & $D A B 2$ & 1601 & disabled homolog 2 & 0.97 & $4.14 \times 10^{-10}$ & 5.3 & 0.0004 & 3.5 & 0.0006 \\
\hline & 218396 at & VPSI3C & 54832 & $\begin{array}{l}\text { vacuolar protein sorting } 13 \\
\text { homolog } C\end{array}$ & 0.97 & $8.54 \times 10^{-10}$ & 4.4 & 0.0012 & 4.8 & 0.0006 \\
\hline & 205383_s_at & ZBTB20 & 26137 & $\begin{array}{l}\text { zinc finger and BTB domain } \\
\text { containing } 20\end{array}$ & 0.97 & $5.52 \times 10^{-10}$ & 4.2 & 0.0011 & 6.7 & 0.0003 \\
\hline & 21922I_at & ZBTB38 & 253461 & $\begin{array}{l}\text { zinc finger and BTB domain } \\
\text { containing } 38\end{array}$ & 0.97 & $2.98 \times 10^{-12}$ & 6.0 & 0.0007 & 6.5 & 0.0003 \\
\hline & 208663_s_at & TTC3 & 7267 & $\begin{array}{l}\text { tetratricopeptide repeat } \\
\text { domain } 3\end{array}$ & 0.97 & $1.19 \times 10^{-9}$ & 3.1 & 0.0021 & 3.1 & 0.0013 \\
\hline & 212070_at & GPR56 & 9289 & $\begin{array}{l}\text { G protein-coupled receptor } \\
56\end{array}$ & 0.97 & $3.78 \times 10^{-10}$ & 3.3 & 0.0007 & 4.3 & 0.0008 \\
\hline & 203216_s_at & MYO6 & 4646 & myosin VI & 0.97 & $2.35 \times 10^{-9}$ & 3.1 & 0.0018 & 2.7 & 0.0012 \\
\hline & 204620_s_at & CSPG2 & 1462 & $\begin{array}{l}\text { chondroitin sulfate } \\
\text { proteoglycan } 2\end{array}$ & 0.97 & $6.97 \times 10^{-11}$ & 104.5 & 0.0001 & 27.8 & 0.0002 \\
\hline
\end{tabular}


Table 2: Transcripts where $97 \%$ of the variance in gene expression is explained by growth conditions (Continued)

\begin{tabular}{|c|c|c|c|c|c|c|c|c|c|c|}
\hline & 212062_at & ATP9A & 10079 & ATPase, Class II, type 9A & 0.97 & $2.73 \times 10^{-9}$ & 2.5 & 0.0002 & 2.7 & 0.0030 \\
\hline & 213775_x_at & ZNF638 & 27332 & zinc finger protein 638 & 0.97 & $2.86 \times 10^{-10}$ & 2.6 & 0.0008 & 3.0 & 0.0005 \\
\hline \multirow{20}{*}{$\begin{array}{l}\text { Down-regulated } \\
\text { and dependent on } \\
\text { growth conditions }\end{array}$} & 213201_s_at & TNNTI & 7138 & troponin T type I & 0.99 & $6.43 \times 10^{-12}$ & -6.9 & 0.0002 & -5.0 & 0.0003 \\
\hline & 212432_at & GRPELI & 80273 & GrpE-like I, mitochondrial & 0.99 & $1.37 \times 10^{-9}$ & -2.3 & 0.0008 & -2.3 & 0.0005 \\
\hline & 209507_at & RPA3 & 6119 & $\begin{array}{l}\text { replication protein A3, } 14 \\
\mathrm{kDa}\end{array}$ & 0.98 & $6.76 \times 10^{-10}$ & -2.2 & 0.0010 & -2.3 & 0.0002 \\
\hline & 209825_s_at & UCK2 & 7371 & uridine-cytidine kinase 2 & 0.98 & $1.09 \times 10^{-9}$ & -2.5 & 0.0019 & -2.3 & 0.0006 \\
\hline & 202533_s_at & DHFR & 1719 & dihydrofolate reductase & 0.98 & $3.51 \times 10^{-9}$ & -2.1 & 0.0013 & -2.0 & 0.0006 \\
\hline & 201577_at & NMEI & 4830 & $\begin{array}{l}\text { non-metastatic cells I, } \\
\text { protein expressed }\end{array}$ & 0.97 & $2.29 \times 10^{-9}$ & -2.1 & 0.0014 & -2.0 & 0.0004 \\
\hline & 208756_at & EIF3S2 & 8668 & $\begin{array}{l}\text { euk. transl. init. factor } 3 \text {, } \\
\text { subunit } 2 \text { beta }\end{array}$ & 0.97 & $1.92 \times 10^{-8}$ & -1.8 & 0.0002 & -1.7 & 0.0013 \\
\hline & 207239_s_at & PCTKI & 5127 & PCTAIRE protein kinase I & 0.97 & $6.29 \times 10^{-9}$ & -1.9 & 0.0017 & -1.9 & 0.0007 \\
\hline & 204I26_s_at & $C D C 45 L$ & 8318 & $\begin{array}{l}\text { CDC45 cell division cycle } 45- \\
\text { like }\end{array}$ & 0.97 & $2.31 \times 10^{-8}$ & -2.0 & 0.0030 & -1.9 & 0.0004 \\
\hline & 219162_s_at & MRPLII* & 65003 & $\begin{array}{l}\text { mitochondrial ribosomal } \\
\text { protein LII }\end{array}$ & 0.97 & $1.37 \times 10^{-9}$ & -2.5 & 0.0010 & -2.2 & 0.0006 \\
\hline & 208847_s_at & ADH5 & 128 & $\begin{array}{l}\text { alcohol dehydrogenase } 5 \text {, chi } \\
\text { polypeptide }\end{array}$ & 0.97 & $5.92 \times 10^{-8}$ & -1.7 & 0.0022 & -1.6 & 0.0007 \\
\hline & 210250_x_at & ADSL & 158 & adenylosuccinate lyase & 0.97 & $4.04 \times 10^{-9}$ & -2.0 & 0.0015 & -2.3 & 0.0012 \\
\hline & 208799_at & PSMB5 & 5693 & proteasome beta 5 subunit & 0.97 & $2.6 \times 10^{-8}$ & -1.9 & 0.0025 & -1.8 & 0.0004 \\
\hline & 221620_s_at & NOMO3 & 408050 & NODAL modulator 3 & 0.97 & $1.64 \times 10^{-9}$ & -2.0 & 0.0015 & -2.3 & 0.0004 \\
\hline & 210519_s_at & NQOI & 1728 & $\begin{array}{l}\mathrm{NAD}(\mathrm{P}) \mathrm{H} \text { dehydrogenase, } \\
\text { quinone I }\end{array}$ & 0.97 & $7.60 \times 10^{-9}$ & -2.1 & 0.0020 & -1.8 & 0.0007 \\
\hline & 208910_s_at & CIQBP & 708 & $\begin{array}{l}\text { splicing factor SF2-associated } \\
\text { protein }\end{array}$ & 0.97 & $1.63 \times 10^{-9}$ & -2.4 & 0.0020 & -2.5 & 0.0008 \\
\hline & 201903_at & UQCRCI & 7384 & $\begin{array}{l}\text { ubiquinol-cytochrome c } \\
\text { reductase }\end{array}$ & 0.97 & $9.25 \times 10^{-9}$ & -1.8 & 0.0019 & -2.1 & 0.0009 \\
\hline & 200039_s_at & PSMB2 & 5690 & $\begin{array}{l}\text { proteasome subunit, beta } \\
\text { type, } 2\end{array}$ & 0.97 & $5.72 \times 10^{-9}$ & -1.9 & 0.0022 & -2.0 & 0.0006 \\
\hline & 217960_s_at & TOMM22 & 56993 & $\begin{array}{l}\text { mitochondrial import } \\
\text { receptor Tom } 22\end{array}$ & 0.97 & $1.04 \times 10^{-8}$ & -2.2 & 0.0007 & -1.9 & 0.0014 \\
\hline & 205691_at & SYNGR3 & 9143 & synaptogyrin 3 & 0.97 & $1.83 \times 10^{-9}$ & -3.1 & 0.0012 & -2.4 & 0.0012 \\
\hline
\end{tabular}

aOnly probe tilings representing genes with annotated functions are provided

bProportion of variance in gene expression due to growth conditions (i.e. cultured cells or xenografts)

cBayes modified $\mathrm{F}$ test (multiple hypothesis corrected)

dFold-change eBenjamini and Hochberg corrected two-tailed Student's t-test 
metabolism (5 transcripts), and the proteosome core complex (6 transcripts) (Additional File 14B).

The decrease in mitochondrial transcripts encoded by the nuclear genome may relate to the relative oxygen deprivation in xenografts relative to cell culture which would cause cells to rely less upon oxidative phosphorylation for their energy needs. The fact that growth conditions play a larger role in the expression of nuclear-encoded mitochondrial genes than the presence of the mitochondrial genome is not surprising if one considers the fact that $\rho^{0}$ cells form mitochondrial structures in the absence of mtDNA. Furthermore, this is consistent with observations that there are no differences in the expression of nuclearencoded oxidative phosphorylation genes in parental and mtDNA-deficient osteosarcoma cells [71]. Interestingly, we could not detect differential transcript levels of nuclear encoded mtDNA polymerase (POLG), previously reported to be decreased on the protein level in HeLa $\rho^{0}$ cells [72], in any pair-wise comparison of experimental grouping performed in this study. However, we did find growth conditions accounted for $73 \%$ of the variance in gene expression (corrected F test $P=8.3 \times 10^{-6}$ and downregulated in xenografts) of the nuclear encoded mitochondrial RNA polymerase POLRMT, which was reported to be down-regulated on the protein level in response to mtDNA depletion in HeLa cells [72].

The above observations, also supported by KEGG (Kyoto Encyclopedia of Genes and Genomes) pathway analyses of the same group of transcripts (Additional File 15), indicate that both glycolysis and aerobic respiration-related genes are less abundant in xenografts relative to culture. This could relate to the cells being cultured in glucose-rich medium that does not reflect the situation found in vivo. In combination, decreased glycolysis and oxidative phosphorylation in xenografts reflects lower energetic demands in vivo. Likewise, the decreased abundance of transcripts related to purine metabolism in xenografts is likely related to slower growth rates in xenografts relative to culture. Decreased purine metabolism could also reflect the absence of the super-physiological levels of glutamine present in cell culture media.

\section{Role of mtDNA mutations in human disorders}

A549 lung cancer cells provide an appealing model system to study mitochondrial function due to their ability to be grown in culture and in tumor xenografts. The potential role of mitochondrial function in cancer was first recognized by Otto Warburg when he observed that cancer cells show a characteristic shift in energy production from oxidative phosphorylation to glycolysis [73]. More recently, there has been increasing appreciation of the possible importance of inherited and somatic mtDNA mutations in cancer [74]. Based on the gene expression profiles observed in this study, $\rho^{0}$ xenograft tumor models could be of particular interest in determining mtDNAmediated responses to specific cancer therapies, such antiangiogenic agents.

In addition, $\rho^{0}$ cells play a critical role in the production of cybrid (cytoplasmic hybrid) cell lines containing specific mutations in mtDNA. While multiple groups have used this elegant system to study mitochondrial function in cultured cells (see reviews $[4,75]$ ), only recently have these cybrids been used in tumor xenografts [64]. Gene expression profiling of such cybrids both in culture and in xenografts could provide valuable data to elucidate further the functional interactions between the nuclear and mitochondrial genomes.

\section{Conclusion}

Although growth conditions had a greater influence on gene expression profiles than the presence of active mitochondria, we identified mtDNA-dependent gene expression profiles that are shared in cultured A549 cells and in xenografts. These profiles indicate that cells with mtDNA alterations have distinct biochemical properties that make them well-suited for elucidating responses to physiological perturbations, such as changes in oxygen and glucose levels, and testing the effects of specialized classes of chemotherapeutic agents. In addition, our studies suggest that gene expression profiling of mtDNA-depleted cells grown culture and in xenografts provide powerful means to investigate possible relationships between mitochondrial activity and gene expression profiles in normal and pathological cells.

\section{Authors' contributions}

JP carried out flow cytometry and immunoassays. PT and XM performed the xenograft studies. PL prepared mtDNAdepleted cells, performed oxygen consumption, flow cytometry, and ELISA assays, and participated in the design of the study. PKD performed gene expression profiling experiments and assisted in data analysis. KR performed mtDNA quantification studies. DMT and KDS analyzed gene expression data. DM and JH conceived of the study, interpreted the data, and wrote the manuscript.

\section{Additional material}

\section{Additional file 1}

Analysis of mitochondrial-encoded RNA transcript levels in A549 and A549 $\rho 0$ xenografts by quantitative RT-PCR. Mitochondrial-encoded RNA transcript levels in A549 and A549 $\rho 0$ xenografts are quantified by RT-PCR.

Click here for file

[http://www.biomedcentral.com/content/supplementary/14712164-9-521-S1.ppt] 


\section{Additional file 2}

Processed gene expression scores for all microarray analyses. Gene expression scores for all microarray experiments described in this manuscript.

Click here for file

[http://www.biomedcentral.com/content/supplementary/1471-

2164-9-521-S2.xls]

\section{Additional file 3}

Volcano plots for gene expression comparisons considered in this study. The relationships between fold changes and P-values for the gene expression comparisons made in this study are provided.

Click here for file

[http://www.biomedcentral.com/content/supplementary/1471-

2164-9-521-S3.ppt]

\section{Additional file 4}

Differentially expressed transcripts in A549 $\rho^{0}$ and A549 cells grown in culture. Probe sets showing differential expression in cultured A549 $\rho^{0}$ and A549 cells are provided.

Click here for file

[http://www.biomedcentral.com/content/supplementary/1471-

2164-9-521-S4.xls]

\section{Additional file 5}

Gene Ontology analysis of transcripts that are differentially expressed in A549 $\rho^{0}$ cells relative to parental A549 cells in culture. Functional categories of transcripts showing differential expression in cultured A549 $\rho^{0}$ and $A 549$ cells are provided.

Click here for file

[http://www.biomedcentral.com/content/supplementary/14712164-9-521-S5.ppt]

\section{Additional file 6}

Analysis of HIF-1 responsive genes in A549 $\rho^{0}$ and A549 cells. Gene expression profiles of HIF-1 responsive genes in A549 $\rho^{0}$ and A549 cells are provided.

Click here for file

[http://www.biomedcentral.com/content/supplementary/1471-

2164-9-521-S6.xls]

\section{Additional file 7}

Transcripts that are differentially expressed in A549 $\rho^{0}$ and A549 cells grown in xenografts. Probe sets showing differential expression in A549 $\rho^{0}$ and $A 549$ xenografts are provided.

Click here for file

[http://www.biomedcentral.com/content/supplementary/1471-

2164-9-521-S7.xls]

\section{Additional file 8}

Gene Ontology analysis of transcripts that are differentially expressed in A549 $\rho^{0}$ cells relative to parental A549 cells in xenografts. Functional categories of transcripts showing differential expression in cultured A549 $\rho^{0}$ and $A 549$ xenografts are provided.

Click here for file

[http://www.biomedcentral.com/content/supplementary/14712164-9-521-S8.ppt]

\section{Additional file 9}

Differential expression in A549 xenografts and A549 cell cultures. Probe sets showing differential expression in A549 xenografts and A549 cell cultures are provided.

Click here for file

[http://www.biomedcentral.com/content/supplementary/1471-

2164-9-521-S9.xls]

\section{Additional file 10}

Differential expression in A549 $\rho^{0}$ xenografts and A549 $\rho^{0}$ cell cultures. Probe sets showing differential expression in A549 $\rho^{0}$ xenografts and A549 $\rho^{0}$ cell cultures are provided.

Click here for file

[http://www.biomedcentral.com/content/supplementary/1471-

2164-9-521-S10.xls]

\section{Additional file 11}

Probe sets where $50 \%$ or more of the variance in gene expression profiles is influenced by mtDNA status. Probe sets where $50 \%$ or more of the variance in gene expression profiles is influenced by mtDNA status are provided.

Click here for file

[http://www.biomedcentral.com/content/supplementary/1471-

2164-9-521-S11.xls]

\section{Additional file 12}

Gene Ontology analysis of down-regulated transcripts in $\rho^{0}$ cells whose variance is strongly influenced by mtDNA status. Functional categories of down-regulated transcripts in $\rho^{0}$ cells whose variance is strongly influenced by mtDNA status are provided.

Click here for file

[http://www.biomedcentral.com/content/supplementary/1471-

2164-9-521-S12.ppt]

\section{Additional file 13}

Probe sets where $90 \%$ or more of the variance in gene expression profiles is influenced by growth conditions. Probe sets where $90 \%$ or more of the variance in gene expression profiles is influenced by growth conditions are provided.

Click here for file

[http://www.biomedcentral.com/content/supplementary/1471-

2164-9-521-S13.xls]

\section{Additional file 14}

Gene Ontology analysis of transcripts whose variance are strongly dependent upon growth conditions. Functional categories of transcripts whose variance are strongly dependent upon growth conditions are provided.

Click here for file

[http://www.biomedcentral.com/content/supplementary/14712164-9-521-S14.ppt]

\section{Additional file 15}

KEGG analysis of differentially expressed genes in A549 $\rho^{0}$ and A549 cells. Biological pathways containing differentially expressed genes in A549 $\rho^{0}$ and A549 cells are provided.

Click here for file

[http://www.biomedcentral.com/content/supplementary/14712164-9-521-S15.xls] 


\section{Acknowledgements}

This work was supported in part by the National Institutes of Health (grant GM 072447 to J.G.H.). Part of this investigation was conducted in a facility constructed with support from Research Facilities Improvement Program Grant Number C06 (RRI0600-0I, CA62528-0I, RRI45I4-0I) from the National Center for Research Resources, National Institutes of Health.

All scaled fluorescent intensity values and .cel files from microarray experiments are available at the National Center for Biotechnology Information (NCBI) Gene Expression Omnibus (GEO) repository http:// www.ncbi.nlm.nih.gov/geo/ under Series Accession Number GSEI0957.

We thank Drs. Anne Chomyn and Giuseppe Attardi at the California Institute of Technology for critical reading of this manuscript and thoughtful discussions. This manuscript is dedicated to Dr. Giuseppe Attardi.

\section{References}

I. Singh KK: Mitochondria damage checkpoint, aging, and cancer. Ann N Y Acad Sci 2006, 1067:182-190.

2. Scarlett DJ, Herst P, Tan A, Prata C, Berridge M: Mitochondrial gene-knockout (rho0) cells: a versatile model for exploring the secrets of trans-plasma membrane electron transport. Biofactors 2004, 20(4): 199-206.

3. Chandel NS, Schumacker PT: Cells depleted of mitochondrial DNA (rho0) yield insight into physiological mechanisms. FEBS Lett 1999, 454(3): 173-176.

4. Bacman SR, Moraes CT: Transmitochondrial technology in animal cells. Methods Cell Biol 2007, 80:503-524.

5. Prokisch H, Andreoli C, Ahting U, Heiss K, Ruepp A, Scharfe C, Meitinger T: MitoP2: the mitochondrial proteome database now including mouse data. Nucleic Acids Res 2006:D705-7I I.

6. Vo TD, Palsson $\mathrm{BO}$ : Building the power house: recent advances in mitochondrial studies through proteomics and systems biology. Am J Physiol Cell Physiol 2007, 292(I):CI64-I77.

7. King M, Attardi G: Human cells lacking mtDNA: repopulation with exogenous mitochondria by complementation. Science 1989, 246(4929):500-503.

8. King MP, Attardi G: Isolation of human cell lines lacking mitochondrial DNA. Methods Enzymol I996, 264:304-3I3.

9. Gilkerson RW, Margineantu DH, Capaldi RA, Selker JM: Mitochondrial DNA depletion causes morphological changes in the mitochondrial reticulum of cultured human cells. FEBS Lett 2000, 474(I): I-4.

10. Arnould T, Mercy L, Houbion A, Vankoningsloo S, Renard P, Pascal T, Ninane N, Demazy C, Raes M: mtCLIC is up-regulated and maintains a mitochondrial membrane potential in mtDNAdepleted L929 cells. FASEB J 2003, I 7( I 4):2 I45-7.

II. Buchet K, Godinot C: Functional FI-ATPase Essential in Maintaining Growth and Membrane Potential of Human Mitochondrial DNA-depleted rho 'Cells. J Biol Chem 1998, 273(36):22983-22989.

12. Amuthan G, Biswas G, Ananadatheerthavarada HK, Vijayasarathy C Shephard HM, Avadhani NG: Mitochondrial stress-induced calcium signaling, phenotypic changes and invasive behavior in human lung carcinoma A549 cells. Oncogene 2002 , 2 I (5 I):7839-7849.

13. Amuthan G, Biswas G, Zhang S, Klein-Szanto A, Vijayasarathy C Avadhani N: Mitochondria-to-nucleus stress signaling induces phenotypic changes, tumor progression and cell invasion. EMBO J 200I, 20(8): 1910-1920.

14. Miceli MV, Jazwinski SM: Nuclear gene expression changes due to mitochondrial dysfunction in ARPE-19 cells: implications for age-related macular degeneration. Invest Ophthalmol Vis Sci 2005, 46(5): I 765-I773.

15. Kulawiec M, Arnouk H, Desouki MM, Kazim L, Still I, Singh KK: Proteomic analysis of mitochondria-to-nucleus retrograde response in human cancer. Cancer Biol Ther 2006, 5(8):967-975.

16. van Waveren C, Sun Y, Cheung HS, Moraes CT: Oxidative phosphorylation dysfunction modulates expression of extracellular matrix - remodeling genes and invasion. Carcinogenesis 2006, 27(3):409-4I8.
17. Biswas G, Tang W, Sondheimer N, Guha M, Bansal S, Avadhani NG: A distinctive physiological role for IkappaBbeta in the propagation of mitochondrial respiratory stress signaling. J Biol Chem 2008, 283( I 8): I 2586-12594.

18. Morais R, Zinkewich-Peotti K, Parent M, Wang H, Babai F, Zollinger $M$ : Tumor-forming Ability in Athymic Nude Mice of Human Cell Lines Devoid of Mitochondrial DNA. Cancer Res 1994, 54( I 4):3889-3896

19. Yu M, Shi Y, Wei X, Yang Y, Zhou Y, Hao X, Zhang N, Niu R: Depletion of mitochondrial DNA by ethidium bromide treatment inhibits the proliferation and tumorigenesis of T47D human breast cancer cells. Toxicol Lett 2007, I 70(I):83-93.

20. Cavalli LR, Varella-Garcia M, Liang BC: Diminished tumorigenic phenotype after depletion of mitochondrial DNA. Cell Growth Differ 1997, 8( I I): I I89-I I 98.

21. Swerdlow RH, Redpath GT, Binder DR, Davis JN 2nd, VandenBerg SR: Mitochondrial DNA depletion analysis by pseudogene ratioing. I Neurosci Methods 2006, I 50(2):265-27I.

22. Herrnstadt C, Clevenger W, Ghosh SS, Anderson C, Fahy E, Miller S, Howell N, Davis RE: A novel mitochondrial DNA-like sequence in the human nuclear genome. Genomics 1999, 60(I):67-77.

23. Papandreou I, Cairns R, Fontana L, Lim A, Denko N: HIF-I mediates adaptation to hypoxia by actively downregulating mitochondrial oxygen consumption. Cell Metab 2006, 3(3): 187-197.

24. Wang Z, Lecane P, Thiemann P, Fan Q, Cortez C, Ma X, Tonev D, Miles D, Naumovski L, Miller R, et al.: Synthesis and biologic properties of hydrophilic sapphyrins, a new class of tumor-selective inhibitors of gene expression. Molecular Cancer 2007, 6(I):9.

25. Magda D, Lecane P, Miller RA, Lepp C, Miles D, Mesfin M, Biaglow JE, Ho VV, Chawannakul D, Nagpal S, et al:: Motexafin gadolinium disrupts zinc metabolism in human cancer cell lines. Cancer Res 2005, 65(9):3837-3845.

26. Smyth GK: Linear models and empirical bayes methods for assessing differential expression in microarray experiments. Stat Appl Genet Mol Biol 2004, 3:.

27. Gentleman RC, Carey VJ, Bates DM, Bolstad B, Dettling M, Dudoit S, Ellis B, Gautier L, Ge Y, Gentry J, et al.: Bioconductor: open software development for computational biology and bioinformatics. Genome Biol 2004, 5( I 0):R80.

28. Hochberg $Y$, Benjamini $Y$ : More powerful procedures for multiple significance testing. Stat Med 1990, 9(7):8। I-8I8.

29. Kirov SA, Zhang B, Snoddy JR: Association analysis for largescale gene set data. Methods Mol Biol 2007, 408:19-33.

30. Zhang B, Schmoyer D, Kirov S, Snoddy J: GOTree Machine (GOTM): a web-based platform for interpreting sets of interesting genes using Gene Ontology hierarchies. BMC Bioinformatics 2004, 5: 16 .

31. Zhang B, Kirov S, Snoddy J: WebGestalt: an integrated system for exploring gene sets in various biological contexts. Nucleic Acids Res 2005:W74I-748.

32. Sirotnak F, Zakowski M, Miller V, Scher H, Kris M: Efficacy of cytotoxic agents against human tumor xenografts is markedly enhanced by coadministration of ZD I 839 (Iressa), an inhibitor of EGFR tyrosine kinase. Clin Cancer Res 2000, 6(I 2):4885-4892.

33. Holmuhamedov E, Jahangir A, Bienengraeber M, Lewis LD, Terzic A Deletion of mtDNA disrupts mitochondrial function and structure, but not biogenesis. Mitochondrion 2003, 3(I): 13-19.

34. Park WH, Han YW, Kim SH, Kim SZ: An ROS generator, antimycin $\mathbf{A}$, inhibits the growth of HeLa cells via apoptosis. J Cell Biochem 2007, I 02(I):98-109.

35. Garber K: Epithelial-to-mesenchymal transition is important to metastasis, but questions remain. I Natl Cancer Inst 2008 , I 00(4):232-233.

36. Peinado H, Portillo F, Cano A: Switching on-off Snail: LOXL2 versus GSK3beta. Cell Cycle 2005, 4(I 2): I 749-I 752.

37. Tukey RH, Strassburg CP: Human UDP-glucuronosyltransferases: metabolism, expression, and disease. Annu Rev Pharmacol Toxicol 2000, 40:581-616.

38. Harding D, Fournel-Gigleux S, Jackson MR, Burchell B: Cloning and substrate specificity of a human phenol UDP-glucuronosyltransferase expressed in COS-7 cells. Proc Natl Acad Sci USA | 988, 85(22):838|-8385.

39. Strassburg CP, Manns MP, Tukey RH: Expression of the UDP-glucuronosyltransferase I A locus in human colon. Identification 
and characterization of the novel extrahepatic UGTIA8. J Biol Chem 1998, 273(15):8719-8726.

40. Mojarrabi B, Mackenzie PI: Characterization of two UDP glucuronosyltransferases that are predominantly expressed in human colon. Biochem Biophys Res Commun 1998, 247(3):704-709.

4I. Turgeon D, Chouinard S, Belanger P, Picard S, Labbe JF, Borgeat P. Belanger A: Glucuronidation of arachidonic and linoleic acid metabolites by human UDP-glucuronosyltransferases. J Lipid Res 2003, 44(6): | | $82-1 \mid$ | $\mid$

42. Jakobs BS, Bogert $C$ van den, Dacremont G, Wanders RJ: Beta-oxidation of fatty acids in cultured human skin fibroblasts devoid of the capacity for oxidative phosphorylation. Biochim Biophys Acta 1994, I 2 I I ( I):37-43.

43. Bell EL, Klimova T, Chandel NS: Targeting the mitochondria for cancer therapy: regulation of hypoxia-inducible factor by mitochondria. Antioxid Redox Signal 2008, 10(3):635-640.

44. Behan $\mathrm{Ai}$, Doyle $\mathrm{S}$, Farrell M: Adaptive responses to mitochondrial dysfunction in the [rho][degree sign] Namalwa cell. Mitochondrion 2005, 5(3): 173-193.

45. Vaux EC, Metzen E, Yeates KM, Ratcliffe PJ: Regulation of hypoxiainducible factor is preserved in the absence of a functioning mitochondrial respiratory chain. Blood 200I, 98(2):296-302.

46. Semenza GL: Oxygen-dependent regulation of mitochondrial respiration by hypoxia-inducible factor I. Biochem J 2007, 405(1):I-9.

47. Eng C, Kiuru M, Fernandez MJ, Aaltonen LA: A role for mitochondrial enzymes in inherited neoplasia and beyond. Nat Rev Cancer 2003, 3(3): 193-202.

48. Carroll VA, Ashcroft M: Role of Hypoxia-Inducible Factor (HIF)-I \{alpha\} versus HIF-2\{alpha\} in the Regulation of HIF Target Genes in Response to Hypoxia, Insulin-Like Growth Factor-I, or Loss of von Hippel-Lindau Function: Implications for Targeting the HIF Pathway. Cancer Res 2006, 66(I 2):6264-6270.

49. Stolze IP, Tian Y-M, Appelhoff RJ, Turley H, Wykoff CC, Gleadle JM, Ratcliffe PJ: Genetic Analysis of the Role of the Asparaginyl Hydroxylase Factor Inhibiting Hypoxia-inducible Factor (HIF) in Regulating HIF Transcriptional Target Genes. J Biol Chem 2004, 279(4I):427I 9-42725.

50. Duarte A, Castillo AF, Castilla R, Maloberti P, Paz C, Podesta EJ, Cornejo Maciel F: An arachidonic acid generation/export system involved in the regulation of cholesterol transport in mitochondria of steroidogenic cells. FEBS Lett 2007, 58 I (2 I):4023-4028.

5I. Di Paola M, Lorusso M: Interaction of free fatty acids with mitochondria: coupling, uncoupling and permeability transition. Biochim Biophys Acta 2006, I 757(9-10): 1330-1337.

52. Kumemura $H$, Harada M, Yanagimoto $C$, Koga $H$, Kawaguchi $T$, Hanada S, Taniguchi E, Ueno T, Sata M: Mutation in keratin 18 induces mitochondrial fragmentation in liver-derived epithelial cells. Biochem Biophys Res Commun 2008, 367(I):33-40.

53. Tang HL, Lung HL, Wu KC, Le AH, Tang HM, Fung MC: Vimentin supports mitochondrial morphology and organization. Biochem J 2008, 4I 0(I): |4|-|46.

54. Park SG, Ewalt KL, Kim S: Functional expansion of aminoacyltRNA synthetases and their interacting factors: new perspectives on housekeepers. Trends Biochem Sci 2005 , 30(10):569-574.

55. Tzima E, Schimmel P: Inhibition of tumor angiogenesis by a natural fragment of a tRNA synthetase. Trends Biochem Sci 2006, $3 I(I): 7-10$.

56. Gu Y, Wang C, Roifman CM, Cohen A: Role of MHC class I in immune surveillance of mitochondrial DNA integrity. J Immunol 2003, I70(7):3603-3607.

57. Kurz T, Terman A, Gustafsson B, Brunk UT: Lysosomes and oxidative stress in aging and apoptosis. Biochim Biophys Acta 2008.

58. Miceli MV, Jazwinski SM: Common and cell type-specific responses of human cells to mitochondrial dysfunction. Exp Cell Res 2005, 302(2):270-280.

59. Creighton CJ, Bromberg-White JL, Misek DE, Monsma DJ, Brichory F, Kuick R, Giordano TJ, Gao W, Omenn GS, Webb CP, et al.: Analysis of Tumor-Host Interactions by Gene Expression Profiling of Lung Adenocarcinoma Xenografts Identifies Genes Involved in Tumor Formation. Mol Cancer Res 2005, 3(3): $119-129$
60. Epstein CB, Waddle JA, Hale Wt, Dave V, Thornton J, Macatee TL, Garner HR, Butow RA: Genome-wide responses to mitochondrial dysfunction. Mol Biol Cell 200I, I 2(2):297-308.

61. Jansen GA, Ofman R, Ferdinandusse S, ljlst L, Muijsers AO, Skjeldal $\mathrm{OH}$, Stokke O, Jakobs C, Besley GT, Wraith JE, et al:: Refsum disease is caused by mutations in the phytanoyl-CoA hydroxylase gene. Nat Genet 1997, I7(2): 190-193.

62. Mihalik SJ, Morrell JC, Kim D, Sacksteder KA, Watkins PA, Gould SJ: Identification of PAHX, a Refsum disease gene. Nat Genet 1997, I7(2): 185-189.

63. Adley BP, Yang XJ: Application of alpha-methylacyl coenzyme A racemase immunohistochemistry in the diagnosis of prostate cancer: a review. Anal Quant Cytol Histol 2006, 28(I): I-I3.

64. Petros JA, Baumann AK, Ruiz-Pesini E, Amin MB, Sun CQ, Hall J, Lim $\mathrm{S}$, Issa MM, Flanders WD, Hosseini SH, et al.: mtDNA mutations increase tumorigenicity in prostate cancer. Proc Natl Acad Sci USA 2005, 102(3):719-724.

65. Delsite R, Kachhap S, Anbazhagan R, Gabrielson E, Singh KK: Nuclear genes involved in mitochondria-to-nucleus communication in breast cancer cells. Mol Cancer 2002, I:6.

66. Jahangir Tafrechi RS, Svensson PJ, Janssen GM, Szuhai K, Maassen JA, Raap AK: Distinct nuclear gene expression profiles in cells with mtDNA depletion and homoplasmic A3243G mutation. Mutat Res 2005, 578(I-2):43-52.

67. Westhuizen FH van der, Heuvel LP van den, Smeets R, Veltman JA, Pfundt R, van Kessel AG, Ursing BM, Smeitink JA: Human mitochondrial complex I deficiency: investigating transcriptional responses by microarray. Neuropediatrics 2003, 34(I):14-22.

68. Jeng JY, Yeh TS, Lee JW, Lin SH, Fong TH, Hsieh RH: Maintenance of mitochondrial DNA copy number and expression are essential for preservation of mitochondrial function and cell growth. J Cell Biochem 2008, I 03(2):347-357.

69. Jazayeri M, Andreyev A, Will Y, Ward M, Anderson CM, Clevenger W: Inducible expression of a dominant negative DNA polymerase-gamma depletes mitochondrial DNA and produces a rho0 phenotype. J Biol Chem 2003, 278(I I):9823-9830.

70. Chevallet M, Lescuyer P, Diemer H, van Dorsselaer A, Leize-Wagner $\mathrm{E}$, Rabilloud $\mathrm{T}$ : Alterations of the mitochondrial proteome caused by the absence of mitochondrial DNA: A proteomic view. Electrophoresis 2006, 27(8): I574-I583.

7I. Duborjal H, Beugnot R, De Camaret BM, Issartel JP: Large functional range of steady-state levels of nuclear and mitochondrial transcripts coding for the subunits of the human mitochondrial OXPHOS system. Genome Res 2002, I 2(12):1901-1909.

72. Seidel-Rogol BL, Shadel GS: Modulation of mitochondrial transcription in response to mtDNA depletion and repletion in HeLa cells. Nucleic Acids Res 2002, 30(9):1929-1934.

73. Warburg O: On the origin of cancer cells. Science 1956, |23(3|9|):309-3|4

74. Brandon M, Baldi P, Wallace DC: Mitochondrial mutations in cancer. Oncogene 2006, 25(34):4647-4662.

75. Swerdlow RH: Mitochondria in cybrids containing mtDNA from persons with mitochondriopathies. J Neurosci Res 2007, 85(I5):3416-3428.

Publish with Bio Med Central and every scientist can read your work free of charge

"BioMed Central will be the most significant development for disseminating the results of biomedical research in our lifetime. "

Sir Paul Nurse, Cancer Research UK

Your research papers will be:

- available free of charge to the entire biomedical community

- peer reviewed and published immediately upon acceptance

- cited in PubMed and archived on PubMed Central

- yours - you keep the copyright 